\title{
Полые револьверные световоды (свойства, технология, применения)
}

И.А.Буфетов, iabuf@fo.gpi.ru, А.Ф. Косолапов, kaf@fo.gpi.ru, А.Д.Прямиков, pryamikov@fo.gpi.ru, A.В.Гладышев, alexglad@fo.gpi.ru, A.Н. Колядин, kolyadin@fo.gpi.ru, A.А. Крылов, krylov@fo.gpi.ru, Ю.П.Яценко, yuriya@fo.gpi.ru, А.С. Бирюков, biriukov@fo.gpi.ru

Научный центр волоконной оптики РАН, www. fibopt.ru, Москва

Полые револьверные световоды (РС) являются особым типом полых световодов с отрицательной кривизной границы сердцевина-оболочка. Их отражающая оболочка обычно состоит из одного слоя капилляров, окружающих сердцевину. Обсуждаются физические механизмы, ответственные за волноводные свойства данных световодов. Приведен обзор оптических свойств и возможных применений полых револьверных световодов. Особое внимание уделено водородным рамановским лазерам среднего ИК-диапазона, основанных на полых револьверных световодах, излучающих в диапазоне 2,9-4,4 мкм.

Ключевые слова: волоконная оптика, технология волоконных световодов, полые световоды, вынужденное комбинационное рассеяние (ВКР)

\section{Hollow-core revolver fibers (properties, design and fabrication, applications)}

I.A.Bufetov, iabuf@fo.gpi.ru, A.F. Kosolapov, kaf@fo.gpi.ru, A.D.Pryamikov, pryamikov@fo.gpi.ru,

A.V.Cladyshev, alexglad@fo.gpi.ru, A.N.Kolyadin, kolyadin@fo.gpi.ru, A.A. Krylov, krylov@fo.gpi.ru,

Yu.P.Yatsenko, yuriya@fo.gpi.ru, A.S.Biryukov, biriukov@fo.gpi.ru

Fiber Optics Research Centre of RAS, www. fibopt.ru, Moscow

Hollow-core revolver fibers (RF) are a special type of hollow optical fibers with negative curvature of the core-cladding boundary. Their reflective cladding usually consists of a single layer of capillaries surrounding the hollow core. The physical mechanisms responsible for the waveguide properties of these fibers are discussed. A review of the optical properties and possible applications of hollow-core revolver fibers is given. Particular attention is paid to hydrogen Raman lasers of the mid-IR spectral range based on hollow-core revolver fibers and emitting in the range of $2.9-4.4 \mu \mathrm{m}$.

Key words: fiber optics, fiber design and fabrication, hollow-core fibers, Raman scattering

\section{1. ВВЕДЕНИЕ}

Револьверные волоконные световоды (РС) - это новый тип волоконных световодов с полой сердцевиной (ПВС), которые впервые были предложены и реализованы в 2011 году в НЦВО РАН [1]. Поперечные сечения полых РС, реализованных до настоящего времени, представлены на рис. 1(а-c). В работе [1] на примере световодов такого типа впервые было введено понятие световодов с отрицательной кривизной границы сердцевина-оболочка. 
Проведенный анализ показал, что именно это свойство (отрицательная кривизна) приводит к значительному снижению оптических потерь. В дальнейшем такое название (световоды с отрицательной кривизной) также стали применять как к световодам с сердцевиной в форме гипоциклоиды [2], так и к позже разработанным световодам, оболочка которых состоит из элементов, похожих на стилизованное изображение конуса с мороженым или парашютика [3]. Основные типы световодов с отрицательной кривизной оболочки представлены на рис. 1(d). Но РС существенно отличаются от других световодов с отрицательной кривизной оболочки тем, что, во-первых, элементы оболочки обладают цилиндрической симметрией (точнее, форма поперечного сечения элементов близка к круговой или эллиптической) и, во-вторых, их можно размещать вокруг сердцевины без соприкосновения друг с другом, что улучшает характеристики световода [4] (ср. рис. 1(а) и рис. 1(b)). Поэтому авторами было предложено именовать световоды с отражающей оболочкой в виде одного слоя цилиндрических капилляров револьверными световодами [5].

Следует еще отметить, что в публикациях, касающихся РС, к ним иногда применяется термин фотонно-кристалические световоды (ФКС). По-видимому, в данном случае этот термин неуместен. Действительно, в ФКС волноводные свойства обусловлены тем, что они имеют в поперечном сечении двумерную периодическую структуру с периодом порядка длины волны, запрещенные зоны которой соответствуют зонам прозрачности световодов. В отличие от ФКС, волноводные свойства РС обусловлены главным образом отражением излучения от структур на границе сердцевинаоболочка, не обладающих трансляционной симметрией. Оптические свойства РС определяются материалом, из которого изготовлен световод, геометрическими параметрами поперечного сечения световода, а также стабильностью этих параметров по длине световода. Свойства РС исследовались численными методами в значительном количестве работ (см., например, [9]).

Данный обзор организован следующим образом: в следующем разделе рассмотрены основные свойства РС с использованием простой аналитической модели; в разделе 3 рассматриваются свойства реальных РС и результаты их численного моделирования; 4-й раздел посвящен технологии изготовления револьверных световодов. В разделе 5 рассматривается применение РС для создания рамановских водородных лазеров среднего ИК-диапазона.

\section{2. ПРИБЛИЖЕННОЕ НАГЛЯДНОЕ ОПИСАНИЕ СВЕТОВЕДУЩИХ СВОЙСТВ РС}

Оптические свойства РС определяются оптическими свойствами материала, из которого сделан световод, и множеством геометрических параметров его поперечного сечения, таких как диаметр

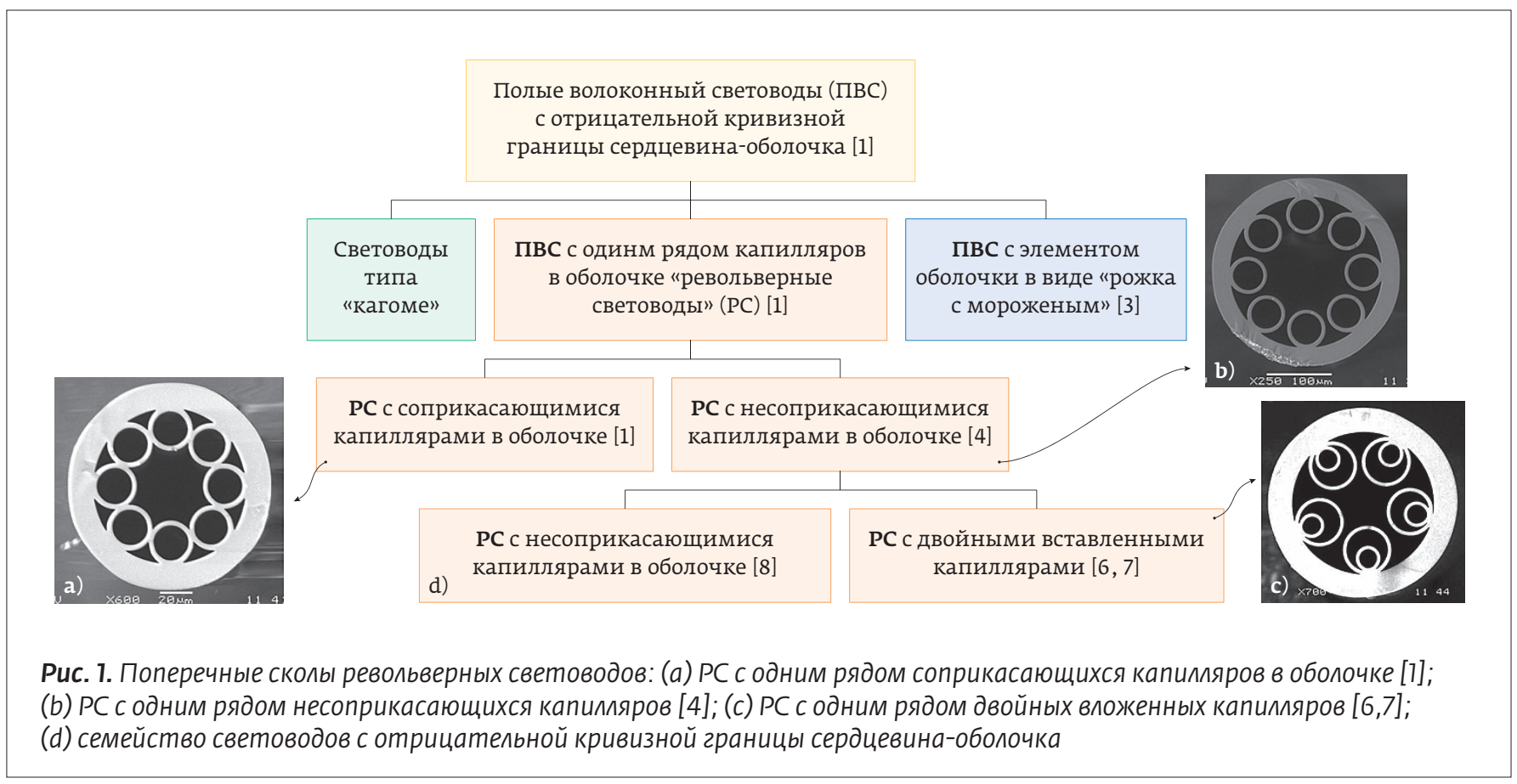


сердцевины, форма и количество капилляров в оболочке, диаметр капилляров, толщин их стенок и т.д. Как следствие, оптические свойства РС с достаточной точностью можно получить только в результате трудоемкого численного моделирования (см. , например, недавний обширный обзор [9] и ссылки в нем). В этом разделе, однако, мы постараемся показать, что основные волноводные свойства РС можно понять, используя своего рода метод последовательных приближений.

В качестве начального приближения к PC можно взять простейшую модель оптического волновода в форме отверстия в диэлектрике (его схема изображена на рис. 2а). Такой полый волновод (ПВ) был подробно рассмотрен в [10]. В этом случае френелевское отражение от поверхности, разделяющей полую сердцевину и диэлектрик, определяет уровень оптических потерь этого световода (рис. 2d, черная линия). Можно значительно снизить оптические потери такого волновода, увеличив коэффициент отражения от границы раздела сердцевина-оболочка, например, путем организации отражения от двух поверхностей, используя в качестве волновода капилляр с тонкой стеклянной стенкой (трубчатый волновод - ТВ), и конструктивной интерференцией излучения, отраженного от обеих поверхностей капилляра. Такой световод был рассмотрен в $[11,12]$, и его можно принять за второе приближение к РС (модель ТВ). В этом случае стенка капилляра служит интерферометром Фабри-Перо, спектр пропускания оптического волокна соответственно приобретает зонную структуру. При выполнении условия резонанса для излучения, падающего на стенку с углом падения, близким к п/2, коэффициент отражения уменьшается, что приводит к большим оптиче-

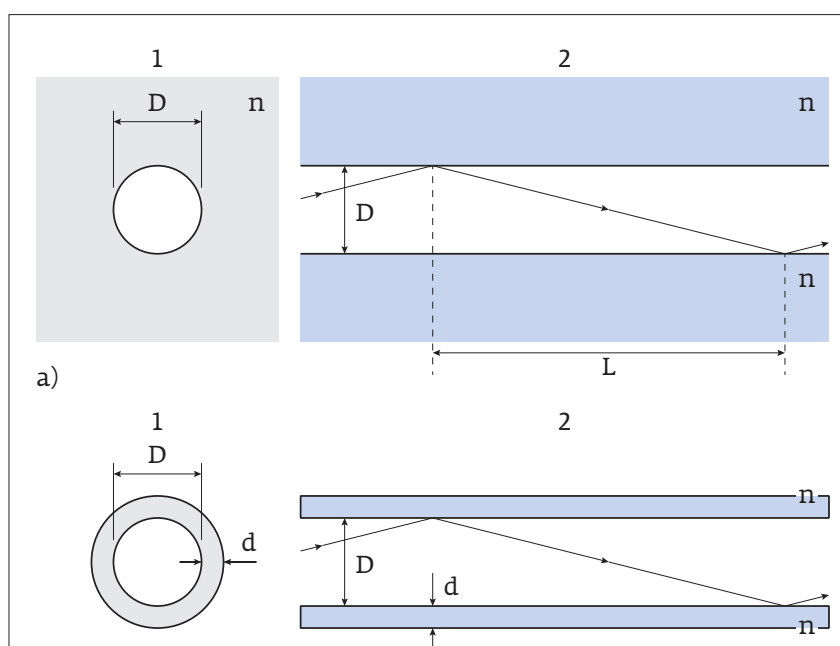

b)

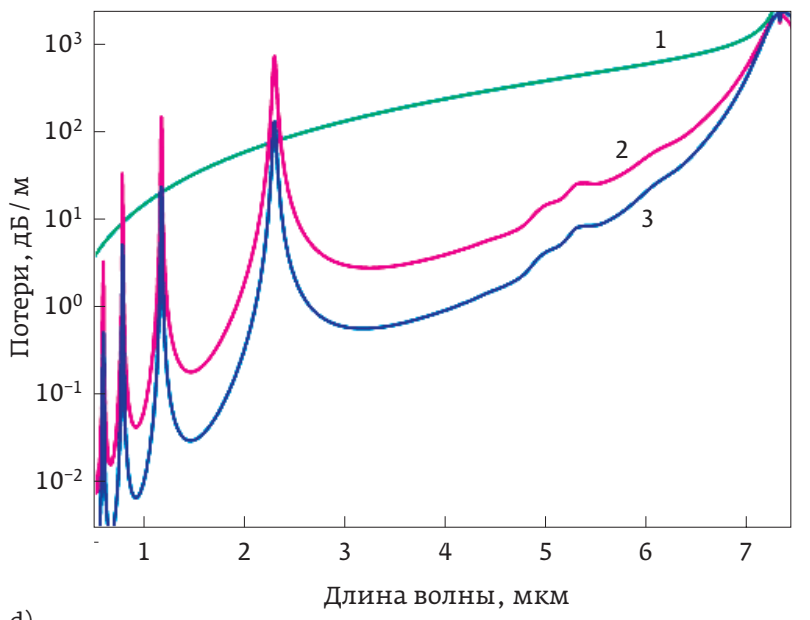

d)

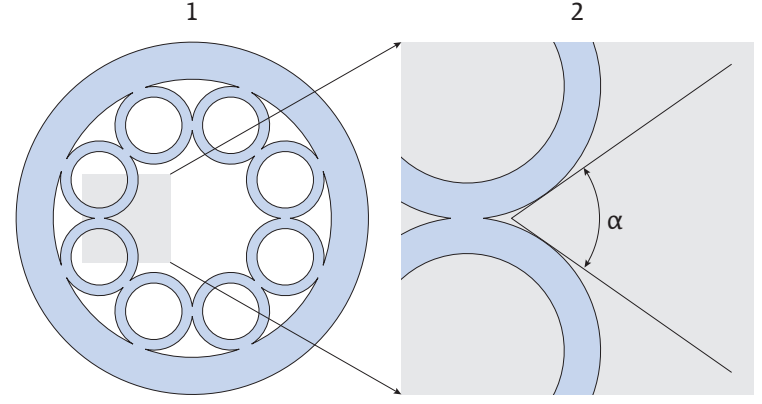

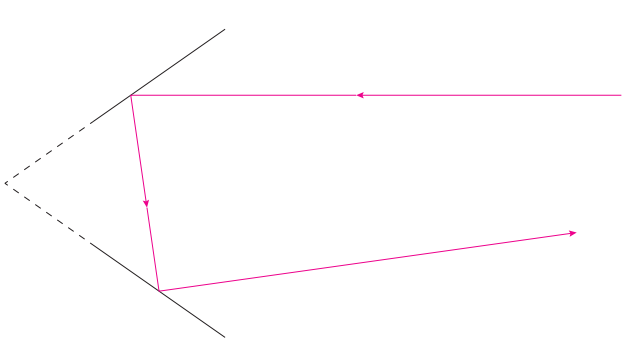

Puc. 2. (a) Поперечное (1) и продольное (2) сечения полого волновода [10]; (b) - поперечное (1) и продольное (2) сечения трубчатого волновода [12]; (c) - поперечное сечение (1) PC [1], аппроксимация части стен отражающих капиляяров зеркальными сторонами угла а (2), схема отражения пуча, распространяющегося вдоль РС от угла с зеркальными сторонами - проекция на поперечное сечение оптического волокна (3); (d) - Расчетный спектр оптических потерь для волноводов из кварцевого стекиа: 1 - полого волновода (ПВ), 2 - трубчатого волновода (ТВ) и 3 - револьверного световода (PC) (дяя всех волноводов диаметр полой сердцевины принят равным 77 мкм, а толщина стенки капиляяров (для ТВ u PC) - 1,15 мкM) 
ским потерям в световоде. Если условие резонанса нарушается (или выполняется условие антирезонанса), коэффициент отражения от стенки капилляра значительно возрастает и формируются зоны прозрачности оптического волокна (см. рис. 2 (d), красная линия).

Позднее такой механизм был фактически заново рассмотрен в [13] и получил сокращенное название ARROW (AntiResonant Reflecting Optical Waveguide: антирезонансный отражающий оптический волновод). Отметим, что возможно дальнейшее усовершенствование резонансно отражающей оболочки волокна (см., например, [14]), которая в случае РС приводит к структуре с двойными вложенными капиллярами $[7,8]$ (см. рис. 1(с)). Наконец, придание тонкой стеклянной стенке на границе сердцевина-оболочка отрицательной кривизны при формировании отражающей оболочки из слоя капилляров (РС [1]) сохраняет зонную структуру спектра пропускания, но приводит к дальнейшему увеличению коэффициента отражения на границе раздела сердцевинаоболочка и, как следствие, к дальнейшему снижению потерь оптического волокна. Качественно это можно объяснить следующим образом. Части стенок капилляров, расположенные ближе к центру сердцевины, действуют как части оболочки в модели ТВ. Части стенок капилляра, которые значительно отклоняются от окружности, вписан ной в сердцевину РС, взаимодействуют с электромагнитным излучением как стороны угла с высоко отражающим покрытием (см. рисунок 2 (с), 2). В лучевом приближении можно сказать, что лучи света отражаются от этих угловых структур (см. рис. 2 (с), 3), и уменьшение угла скольжения лучей при отражении по сравнению с отражением от участков капилляров, близких к центру световода, приводит к существенному снижению оптических потерь по сравнению с моделью ТВ.

Кроме того, когда капилляры в оболочке отстоят друг от друга на расстояние $d<<(2 \cdot \pi) / k_{\perp}$, где $k_{\perp}$ - составляющая волнового вектора, перпендикулярная оси волокна, условия распространения излучения вдоль сердцевины практически не изменяются по сравнению с оболочкой с касающимися капиллярами. Это примерно соответствует удалению вершины "зеркального" угла, обозначенного пунктирной линией на рис. 2 (с), 3. Однако в этом случае возбуждение мод оболочки, связанных с участками контакта капилляров друг с другом, будет существенно снижено. Все это приводит в результате к дальнейшему эффективному снижению оптических потерь в РС. На экспери- менте данный результат впервые был получен в [4].

Высокий коэффициент отражения на границе раздела сердцевина-оболочка уже в случае ПВ приводит к тому, что моды в ПВ аналогичны модам в идеально проводящих металлических световодах, когда длина волны излучения далека от длины волны отсечки. Эта особенность была отмечена в [10]. РС, как и любые другие световоды с отрицательной кривизной оболочки, характеризуются еще большим коэффициентом отражения от границы раздела сердцевина-оболочка. По этой причине мощность излучения в РС еще более сконцентрирована в полой сердцевине. Оптическое поглощение материала, из которого сделан РС, в этих обстоятельствах отходит на второй план, в то время как потери в РС главным образом обусловлены вытеканием излучения из сердцевины и определяются в основном геометрическими параметрами оболочки и условиями френелевского отражения от нее. Это означает, что РС могут использоваться для транспортировки излучения и наблюдения различных оптических явлений даже в тех спектральных областях, где материал световода (например, кварцевое стекло) является непрозрачным.

Как показывают упрощенные модели РС, которые обсуждались выше, возможность передачи лазерного излучения с низкими потерями в РС в ультрафиолетовом и среднем ИК-диапазонах спектра обусловлена главным образом величиной (с учетом изменений по спектру) как действительной $\operatorname{Re}(n(\lambda))$, так и мнимой $\operatorname{Im}(n(\lambda))$ частей показателя преломления материала световода. Отметим, что выбор материала для РС в значительной степени ограничен: до настоящего времени РС изготавливались из кварцевого, халькогенидного [15] и органического стекол (полиметилметакрилат) [16]. На волноводные свойства также влияет отношение длины волны к основным геометрическим размерам РС, таким как диаметр полой сердцевины $D_{\text {core }}$ и толщина стенок капилляров $d$. Однако это соотношение может быть оптимизировано для интересующей длины волны в процессе создания световода.

Для РС, сделаных из кварцевого стекла, оптические потери в среднем ИК-диапазоне растут с длиной волны до длины волны 7,3 мкм (см. рисунок 2d). Это происходит по двум причинам: $\operatorname{Re}\left(n_{\mathrm{SiO}_{2}}\right)$ уменьшается [17], что приводит к уменьшению коэффициента френелевского отражения от границы раздела воздух-стекло (здесь коэффициент френелевского отражения в основном определяется зна- 
чением $\operatorname{Re}\left(n_{\mathrm{SiO}_{2}}\right)$, поскольку значение $\operatorname{Im}\left(n_{\mathrm{SiO}_{2}}\right)$ мало по сравнению с единицей). Кроме того, поглощение излучения в стенке кварцевого капилляра начинает проявляться в области длин волн около 5 мкм. В результате эффективность механизма ARROW уменьшается, и значение коэффициента отражения от стенки капилляра начинает снижаться, приближаясь к значениям, характерным для модели ПВ. Это также справедливо для больших длин волн в среднем ИК-диапазоне, за исключением небольших областей около 7,3 мкм и, возможно, около 9 мкм и 20 мкм. Отметим, что на этих длинах волн значение $\operatorname{Re}\left(n_{\mathrm{SiO}_{2}}\right)$ близко к единице и отражение на границе воздух-стекло практически отсутствует, так что полые микроструктурированные световоды (ПМС) из кварцевого стекла не могут демонстрировать на этих длинах волн какие-либо волноводные свойства.

В ближнем ИК- и в видимом диапазонах световоды из кварцевого стекла, как и само кварцевое стекло, работают наилучшим образом. При смещении вдоль длин волн в сторону УФ-диапазона значение $\operatorname{Re}\left(n_{\mathrm{SiO}_{2}}\right)$ увеличивается, что снижает оптические потери в РС. Однако на длине волны около 150 нм значение $\operatorname{Im}\left(n_{\mathrm{SiO}_{2}}\right)$ резко возрастает, что, как и в среднем ИК-диапазоне, приводит к "выключению" интерференционного механизма ARROW. B результате значение оптических потерь увеличивается до уровня, который определяется только одним отражением на границе раздела сердцевина-оболочка (ПС). Тем не менее полученные результаты показывают, что РС на основе кварцевого стекла можно использовать вплоть до вакуумного ультрафиолета (124 нм) [18]. В случае РС, изготовленных из халькогенидного стекла, волноводные свойства РС были продемонстрированы вплоть до длин волн 10 мкм [15]. Терагерцевое излучение может также передаваться по волноводам из полимеров (например из полиметилметакрилата), аналогичных по структуре РС [16].

\section{3. РС С РАЗЛИЧНЫМИ КОНСТРУКЦИЯМИ ОТРАЖАЮЩЕЙ ОБОЛОчКИ}

Спектральные свойства РС были детально исследованы путем численного моделирования и экспериментально. Оптические потери являются одним из основных параметров РС. На рис. 3 показаны экспериментально достигнутые к настоящему времени оптические потери в ПВС различных типов из кварцевого стекла, в том числе и в РС. Для сравнения также показан спектр поглощения чистого кварцевого стекла. Как видно на рис. 3, в уль- трафиолетовом диапазоне оптические потери РС (рис. 3, данные 15) приближаются к уровню поглощения чистого кварцевого стекла (рис. 3, данные 2). Отметим, что ПВС, имеющие квадратную (данные 14) и гексагональную (данные 11) сердцевину без отрицательной кривизны, демонстрируют здесь свойства, подобные РС. В ближнем ИК-диапазоне световоды с фотонными запрещенными зонами (ФКС) (данные 6) имеют самый низкий уровень оптических потерь. На длинах волн 3-4,4 мкм в среднем ИК-диапазоне и РС (данные $5,16,17)$ и ПВС с элементами структуры оболочки в форме "рожка с мороженным" (данные 8) показывают одинаковые оптические потери, которые ниже, чем в чистом кварцевом стекле (данные 3). Стоит отметить, что РС (рис. 3 , данные 4, 16) являются единственными полыми кварцевыми световодами, демонстрирующими оптическое пропускание на длинах волн выше 4,4 мкм.

Рис. 3 показывает, что РС расширяют применимость кварцевых волоконных световодов до среднего ИК-диапазона (выше 3 мкм). Например, на длине волны 4,4 мкм, где коэффициент поглощения кварцевого стекла составляет около 4000 дБ/ м (рис. 3, данные 3), РС, изготовленные из кварцевого стекла, позволили продемонстрировать опти-

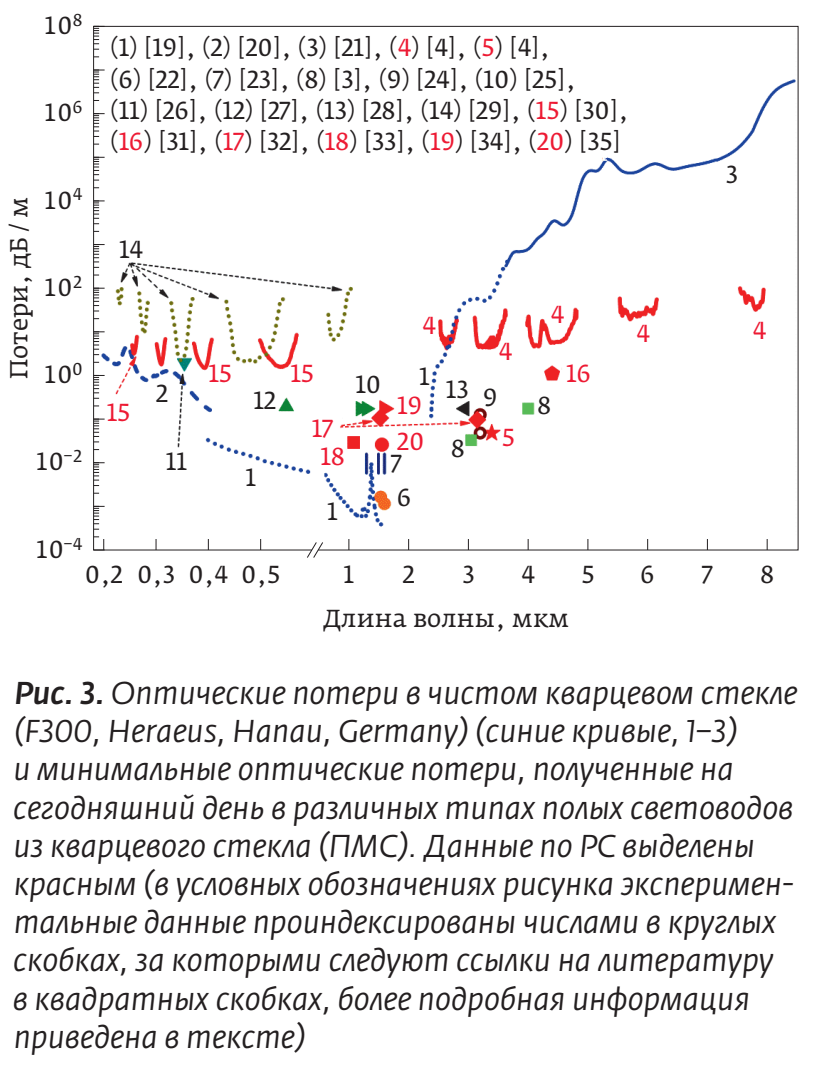


ческие потери на уровне 1 дБ/ м (рис. 3, данные 16). Следует отметить, что, по сравнению с РС, изготовленными из кварцевого стекла, твердотельные световоды из стекол специальных типов могут иметь более низкие оптические потери в среднем ИК-диапазоне. Например, оптические потери, менее 0,1 дБ/м, были продемонстрированы во фторидных световодах в спектральном диапазоне 2,0-4,5 мкм [36] и в халькогенидных световодах на длинах волн до 6,5 мкм $[37,38]$. В более длинноволновом диапазоне (8-16 мкм) световоды из галогенидов серебра демонстрируют оптические потери ниже 1 дБ/м [39]. Как правило, полностью стеклянные некварцевые световоды, предназначенные для среднего ИК, способны обеспечивать в 10-1000 раз более низкий уровень потерь чем, собственно, потери в РС из кварцевого стекла. Тем не менее использование РС из кварцевого стекла может быть выгодным на длинах волн до 5 мкм, так как разумный уровень оптического затухания может быть достигнут с использованием хорошо разработанной технологии. Более того, порог разрушения в РС намного выше в сравнении с полностью стеклянными некварцевыми световодами для среднего ИК. Таким образом, полые РС незаменимы для приложений, связанных с транспортировкой излучения высокой мощности.

\section{1. РС с касающимися и некасающимися капиллярами в оболочке}

После первых РС, которые имели соприкасающиеся капилляры в оболочке (рис. 1 (а)) [1], был предложен модифицированный РС c несоприкасающимися капиллярами в оболочке (рис. 1 (b)) [4]. Оказалось, что такая структура РС имеет меньшие оптические потери, чем предыдущая. Впоследствии PC с несоприкасающимися капиллярами в оболочке использовались во многих работах (см., например, [32, 34, 40]).

Численным моделированием было показано, что отсутствие точек соприкосновения между капиллярами устраняет дополнительные резонансы в полосах пропускания (рис. 4). В ходе численного моделирования было проведено сравнение двух моделей РС. В них все геометрические параметры РС были идентичны, за исключением того, что промежутки между капиллярами в одном из световодов (красная линия на рис. 4) были заполнены стеклом (см. вставку на рисунке 4). Таким образом, вся разница между двумя кривыми на рис. 4 (а) определяется наличием узлов между капиллярами в оболочке. Оболочка каждого волокна состояла из восьми капилляров, которые имели внешний и внутренний диаметры 63 мкм и 51 мкм соответственно. Минимальное расстояние между несоприкасающимися капиллярами составляло 1,3 мкм. Спектры потерь рассчитывались в спектральном диапазоне 3-6,5 мкм для обоих РС. Результаты моделирования показывают, что наличие узлов между капиллярами приводит к увеличению оптических потерь световода из-за возникновения резонансов между модами сердцевины и оболочки.

Впервые РС с отдельными капиллярами в оболочке был изготовлен в [4]. Световод имел наружный диаметр 290 мкм, диаметр сердцевины 110 мкм и толщину стенки капилляров 6 мкм. Сечение световода и измеренный спектр оптических потерь приведены на рис. 5. Видно, что средний уровень оптических потерь, измеренных в спектральном диапазоне 2,5-5 мкм, составлял около 4-5 дБ/м. В более длинноволновом диапазоне около 5,8 и 7,7 мкм измеренные потери составили 30 и 50 дБ/м соответственно. Полосы пропускания при 3,3 и 4,3 мкм имеют ряд пиков поглощения, которые связаны с линиями поглощения $\mathrm{HCl}$ (аналогично работе [3]) и атмосферного $\mathrm{CO}_{2}$ соответственно. Оптическое поглощение кварцевого стекла также показано для сравнения (рис. 5, черная кривая).

Для анализа результатов эксперимента было проведено численное моделирование оптических потерь для основной моды этого световода (рис. 5, зеленая кривая). Как видно из рис. 5, расчетные и экспериментально полученные края

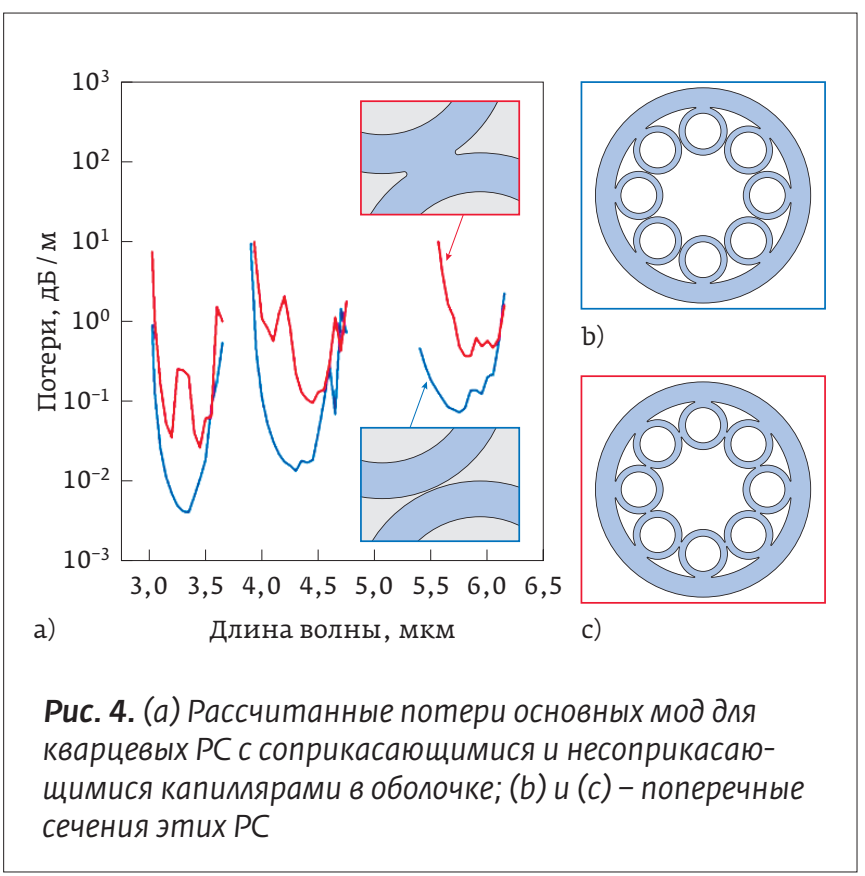




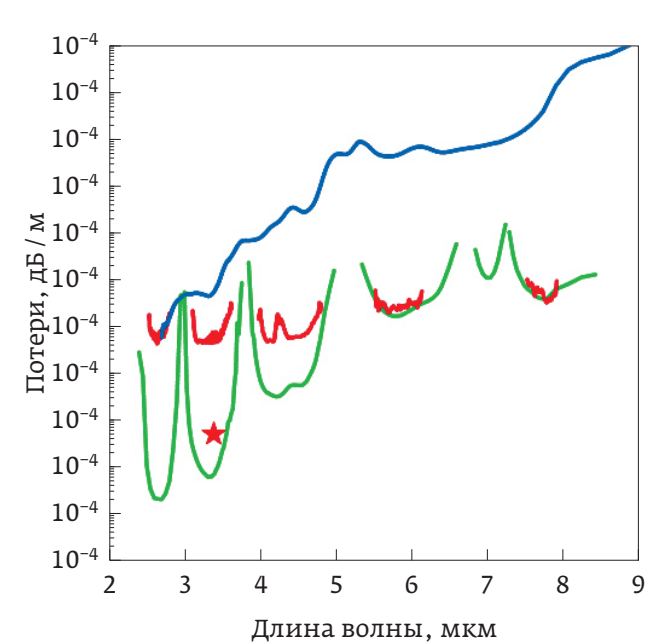

a)
- Расчетные потери для основной моды
- Экспериментальные потери в широком
диапазоне на коротких кусках световода
- Потери в кварцевом стекле
Ł Потери измеренные с помощью
Не-Ме-лазера на большой длине световода

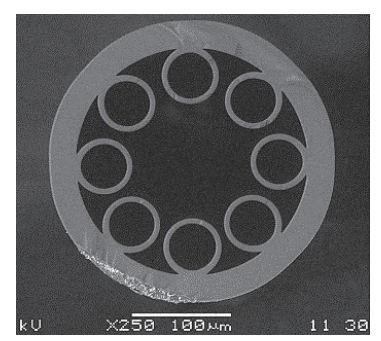

b)
Pис. 5. (а) измеренные потери (красный); потери, измеренные с помощью Не-Ne пазера на 3,39 мкм (красная звездочка); материальные потери в кварцевом стекле (синий); расчетные потери основной моды РС (зеленый); (b) поперечное сечение $P C$, $D_{\text {core }}=110$ мкм, толщины стенок капиляяров $d=6$ мКм полос пропускания хорошо совпадают. С другой стороны, данные по минимальному уровню потерь в полосах пропускания существенно отличаются. По-видимому, это происходит главным образом из-за присутствия мод более высокого порядка в процессе измерения потерь (во время эксперимента для возбуждения короткого отрезка световода использовался многомодовый источник света). Такое объяснение согласуется с результатами измерений потерь методом "cut-back" с помощью маломодового Не-Ne-лазера (3,39 мкм) в световоде длиной 11 м. Этот эксперимент показал, что на указанной длине волны состав мод в световоде стабилизируется на длине световода более 3 м. Когда в световоде присутствуют только первые несколько мод, уровень потерь составляет всего 50 дБ/км (красная звездочка на рисунке 5), что намного ближе к уровню потерь, рассчитанному для основной моды на 3,39 мкм. Таким образом, уровень реальных потерь в световоде при маломодовом режиме распространения света достаточно низок и может быть оценен с использованием рассчитанного спектра потерь (рис. 5, зеленые кривые).

\section{2. РС С ОДИНОЧНЫМИ И ДВОЙНЫМИ ВЛОЖЕННЫМИ КАПИЛЛЯРАМИ}

В среднем ИК спектральном диапазоне материальные потери кварцевого стекла изменяются от 0,1 дБ/м до $10^{5}$ дБ/м для длин волн от 2 мкм до 6 мкм [41]. Таким образом, полные потери в РС из кварцевого стекла, начиная с длин волн >2 мкм, начинают все в большей степени определяться материальными потерями кварцевого стекла. При этом конструкции обыкновенных револьверных световодов ((рис. 1(a) и (b)) и све- товодов с вложенными капиллярами в оболочке (рис. 1(c)) ведут себя неодинаково в области больших материальных потерь кварцевого стекла [41]. В случае РС с вложенными капиллярами пропускание излучения осуществляется с потерями меньшими, чем в обыкновенном РС, до определенной длины волны в среднем ИК-диапазоне. В этом случае второй капилляр работает как вторая отражающая поверхность и увеличение коэффициента отражения от оболочки дает выигрыш в полных потерях по сравнению с обыкновенным РС (с одиночными капиллярами, рис. 1(a, b)). При дальнейшем увеличении длины волны и, соответственно, уровня материальных потерь, вторая отражающая стенка вложенного капилляра РС уже не может за счет интерференционных эффектов компенсировать рост материальных (и полных потерь, соответственно). Именно поэтому первый водородный рамановский лазер с длиной волны генерации 4,4 мкм [31, 42, 43] был построен на основе обыкновенного РС с одним слоем капилляров. В работе [4] было показано, что револьверные световоды из кварцевого стекла позволяют пропускать излучение вплоть до длины волны 8 мкм с потерями порядка нескольких десятков дБ/м (рис. 5). Для практических применений РС из кварцевого стекла в данной области спектра такой уровень потерь слишком высок. Поэтому полагается, что для РС, изготовленных из кварцевого стекла, граница применимости ограничена длиной волны приблизительно 5 мкм, так как в области этой длины волны материальные потери кварцевого стекла возрастают примерно на порядок по сравнению с предыдущими значениями (рис. 5(а)). Таким образом, в области прозрачности кварце- 
вого стекла РС с двойными вложенными капиллярами демонстрируют меньшие оптические потери по сравнению с РС с одиночными. В области высоких оптических потерь в кварцевом стекле РС с одиночными капиллярами имеют преимущество. Кроме того, помимо вышесказанного, необходимо всегда принимать во внимание влияние изгибных потерь.

Для того чтобы пропускать излучение по револьверному световоду из кварцевого стекла в среднем ИК-диапазоне, в районе длины волны 5 мкм, с приемлемыми потерями на уровне 1 дБ/м, необходимо проводить оптимизацию геометрической структуры оболочки: толщин стенок капилляров, дающих нужную зону пропускания на данной длине волны, расстояний между капиллярами, их количество и размер полой сердцевины. Другим путем решения задачи пропускания излучения в револьверных световдах в среднем ИК-диапазоне с малыми потерями является использование специальных стекол (халькогенидных, теллуритных), обладающих в этом диапазоне небольшими материальными потерями.

\section{3. Свойства РС в УФ-диапазоне длин волн}

Несколько иная ситуация наблюдается при пропускании излучения в УФ спектральном диапазоне. Измеренные материальные потери кварцевого стекла в спектральном диапазоне от 200 до 400 нм не столь велики, как в среднем ИК спектральном диапазоне, и варьируются в интервале от нескольких десятых до $\approx 10$ дБ/м [20]. Поэтому, сравни вая роль волноводных и материальных потерь, можно сказать, что волноводные потери играют основную роль в данном случае. Таким образом, основным механизмом, позволяющим снижать уровень полных потерь в данном случае, является оптимизация геометрической структуры РС из кварцевого стекла. С одной стороны, низкие волноводные потери можно получить за счет увеличения диаметра полой сердцевины, имеющей размеры, значительно больше рассматриваемой длины волны. С другой стороны, это ведет к возбуждению большого количества мод полой сердцевины из-за неоднородностей конструкции световода, возникающих при его вытяжке, а также к суживанию зон пропускания световода [30]. Поэтому, как и в случае РС в среднем ИК-диапазоне, для соблюдения всех вышеуказанных условий необходимо выбирать некоторую оптимальную конструкцию с определенной толщиной стенки капилляра оболочки, с определенными рассто- яниями между капиллярами и с определенным размером диаметра полой сердцевины. Использование РС с вложенными капиллярами в этом спектральном диапазоне представляется маловероятным ввиду сложности их изготовления (например, сохранения размера и формы капилляра оболочки при вытяжке). Кроме этого, важно также и число капилляров в оболочке. Например, в работе [44] был продемонстрирован волноводный режим в РСе из кварцевого стекла с четырьмя капиллярами в оболочке с потерями на длине волны 350 нм около 0,5 дБ/м. Но при этом размер капилляров, по сравнению с диаметром сердцевины, таков, что потери на изгиб должны быть велики. В РС, продемонстрированном в работе [30], с диаметром полой сердцевины 15 мкм и восемью капиллярами в оболочке, наблюдались несколько зон пропускания в УФ-диапазоне от 200 до 350 нм. Потери при этом были на уровне 1-2 дБ/м. Авторы объясняют такой достаточно высокий уровень волноводных потерь несовершенством конструкции вытянутого световода. В заключение стоит сказать о многоугольном световоде, локализующем свет за счет так называемого double antiresonant mechanism [29]. Авторы [29] предложили использовать световод с квадратной границей сердцевина - оболочка, подвешенной на специальных распорках, прикрепленных к опорной трубе. Такой световод дал систему зон пропускания, вплоть до длины волны 241 нм, с потерями, сравнимыми с потерями в РС, представленном в работе [30].

\section{4. ТЕХНОЛОГИЯ ИЗГОТОВЛЕНИЯ РС}

До настоящего времени большинство волоконных световодов револьверного типа было изготовлено из кварцевого стекла. Существенно большие трудности возникают при изготовлении РС из стекол других типов, например, халькогенидных. Рассмотрим процессы изготовления этих световодов последовательно.

\section{1. Технология изготовления РС на основе кварцевого стекла}

Одним из существенных преимуществ РС перед, например, светводами типа Кагоме является более простая структура световода и, соответственно, более простая технология их изготовления, поскольку отражающая оболочка содержит только один слой капилляров.

Заготовки для РС изготавливаются методом сборки из капилляров. Для этого в опорную трубу вставляются предварительно изготовленные капилляры (см. рис. 6). При этом капилляры могут 
либо упираться друг в друга (рис. 6а), либо в начале и в конце сборки между капиллярами могут быть вставлены дополнительные вспомогательные распирающие элементы (рис. 6b). В первом случае получается световод с соприкасающимся капиллярами [1] либо ісе-сream структура [3], во втором случае возможно получение револьверного световода с разведенными капиллярами [4]. Кроме того, для изготовления световода могут использоваться как простые одиночные капилляры (рис. ба), так и капилляры более сложной конструкции, например, двойные вложенные капилляры (рис. 6b). В результате получаются или РС с одиночными капиллярами, которые лучше работают в областях, где собственное поглощение кварцевого стекла играет большое значение, или РС с двойными вложенными капиллярами, которые обеспечивают меньшие оптические потери в спектральных областях, где поглощение в кварцевом стекле еще не является определяющим для потерь в РС.

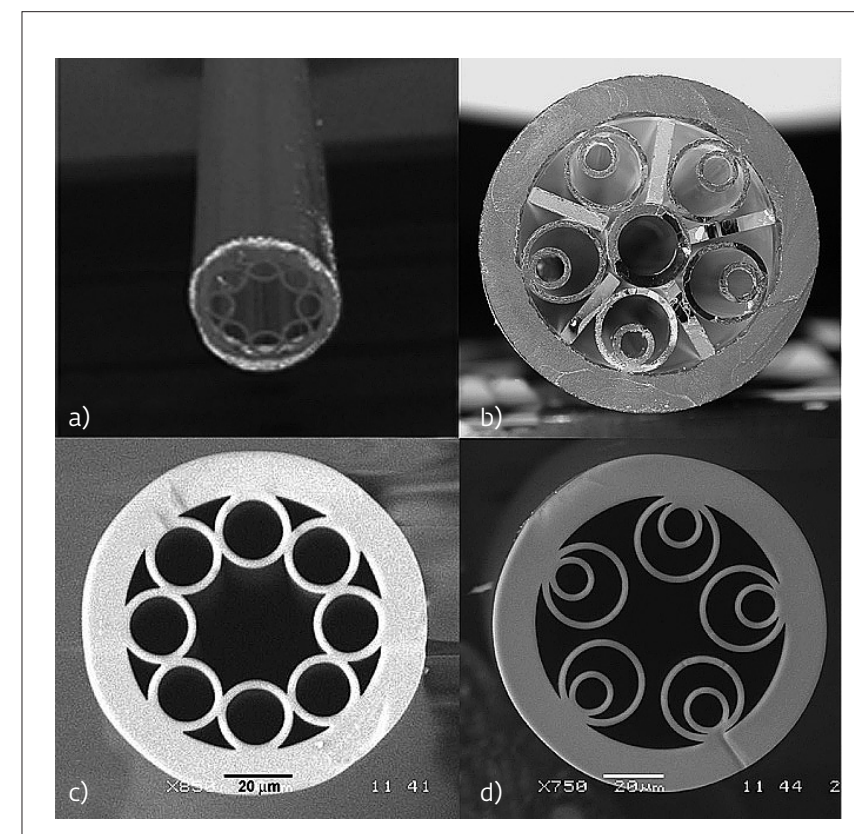

Puc. 6. Поперечные сечения оптических элементов на основных этапах изготовления РС с двойными вложенными и одиночными капиляярами: (a) заготовка РС с одиночными капиляярами, прилегающими друг к другу; (b) собранная заготовка РС с кварцевыми элементами между двойными капиплярами, -25 мм; (c) изображение сечения вытянутого РС с касающимися капиляярами (из заготовки на рис. 6а), полученное с помощью сканирующего электронного микроскопа (СЭМ); (d) изображение сечения вытянутого РС с двойными вложенными несоприкасающимися капиялярами, 710 мкм (из заготовки на рис. 6b), полученное с помощью сканирующего электронного микроскопа
После этапа сборки заготовка проходит первичную тепловую обработку с целью приваривания капилляров к несущей трубке, однако данная процедура необязательна, например, в [15] при изготовлении РС из халькогенидного стекла приваривание капилляров не производилось из-за опасения растрескивания заготовки после такой термообработки.

В процессе вытяжки волоконного световода для предотвращения схлопывания капилляров под действием сил поверхностного натяжения в них подается избыточное давление газа. Обычно для этого используется регулятор давления газа, который подсоединяется ко всем капиллярам и поддерживает необходимое избыточное давление. У данного подхода имеется существенный недостаток, не позволяющий изготовлять РС со строго одинаковыми капиллярами. Очевидно, что капилляры, используемые для изготовления заготовки, неизбежно имеют отклонения размеров от среднего значения, следовательно, силы поверхностного натяжения, стремящиеся схлопнуть капилляр, будут различаться для каждого капилляра, а значит, для каждого капилляра необходимо использовать индивидуальную систему регулировки давления, что на практике трудно реализуемо. Как правило, на практике используется подача одинакового давления во все капилляры, при этом имеющийся в заготовке разброс размеров капилляров увеличивается в процессе вытяжки световода (см. рис. 7, верхняя стрелка). Это происходит потому, что капилляры, имеющие диаметр меньше среднего, в процессе вытяжки еще более

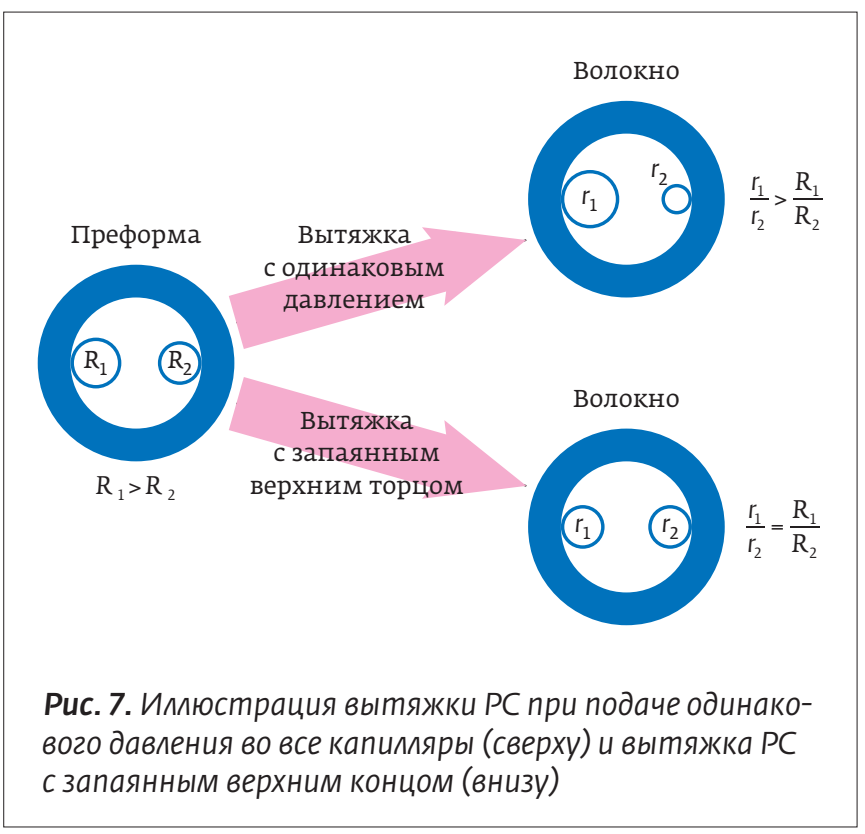


уменьшают свой относительный размер, а капилляры с размером выше среднего увеличиваются в процессе вытяжки (под средним понимаем такой диаметр капилляра, при котором силы поверхностного натяжения будут уравновешены вну тренним избыточным давлением). Тем не менее использование высококачественных труб (например, кварцевых труб фирмы Heraeus) в качестве "исходного сырья" для изготовления капилляров позволяет добиваться неплохих результатов даже по технологии с подачей одинакового давления во все капилляры.

Существует альтернативный подход к вытяжке микроструктурированных световодов, который применим и к вытяжке РС. Метод называется "технология вытяжки с запаянным верхним торцом" (рис. 7, нижняя стрелка) [45]. Суть данной технологии заключается в том, что полости заготовки запаиваются с верхнего торца заготовки. Таким образом, каждая полость изначально содержит некоторое количество газа и все полости изолированы друг от друга. В процессе вытяжки нижняя часть заготовки разогревается, давление в полостях увеличивается, а сами полости расширяются. При этом степень увеличения объема полости определяется отношением температуры верхнего торца заготовки к температуре в зоне перетяжки (в луковице) и в первом приближении не зависит от диаметра полости. Другими словами, все полости заготовки в каждый момент времени увеличиваются в одинаковое количество раз [45]. Таким образом, разброс размеров капилляров, имеющийся в заготовке РС, сохраняется и в световоде. Тогда как при использовании технологии с подачей одинакового давления во все капилляры отклонение размеров капилляров от среднего значения увеличивается при вытяжке световода.

Существенным недостатком "технологии вытяжки с запаянным верхним торцом" является то, что в процессе вытяжки верхний, изначально холодный торец заготовки, приближается к горячей зоне и разогревается, и в результате степень раздувки полостей уменьшается. То есть РС, вытянутые по данной технологии, имеют плавно изменяющийся размер капилляров по длине световода.

\section{2. Технология изготовления и свойства РС на основе халькогенидных стекол}

Хотя в работе [4] и был продемонстрирован волноводный режим распространения в револьверном световоде, изготовленном из кварцевого стекла, вплоть до длины волны 7,9 мкм, опти- ческие потери в таких револьверых световодах составляют более 10 дБ/м на длинах волн более 4,5 мкм. По-видимому, из кварцевого стекла невозможно сконструировать полый волоконный световод с разумными размерами, который бы имел оптические потери на уровне $\approx 1$ дБ/ м на длинах волн более $\approx 5$ мкм. Поэтому для продвижения в более длинноволновый диапазон спектра необходимо разрабатывать полые световоды из других материалов. Теллуритные стекла имеют более широкую область прозрачности [46]. Их использование позволяет продвинуться до длины волны 5,5-6 мкм. Но более радикальный выигрыш дает использование бескислородных стекол, в частности халькогенидных.

Ситуация с технологией при этом значительно усложняется. Как качество исходных труб из халькогенидного стекла, так и их физические свойства приводят к тому, что получить РС из них с геометрическими параметрами, сравнимыми даже не по точности, а по качеству с параметрами РС из кварцевого стекла, представляет собой значительно более сложную задачу (что видно в сравнении поперечных сечений кварцевых световодов на рис. 6 (c) и (d) и халькогенидных на рисунках 8 (b) и (d)). Впервые револьверный световод из халькогенидного стекла был изготовлен в 2011 году [15].

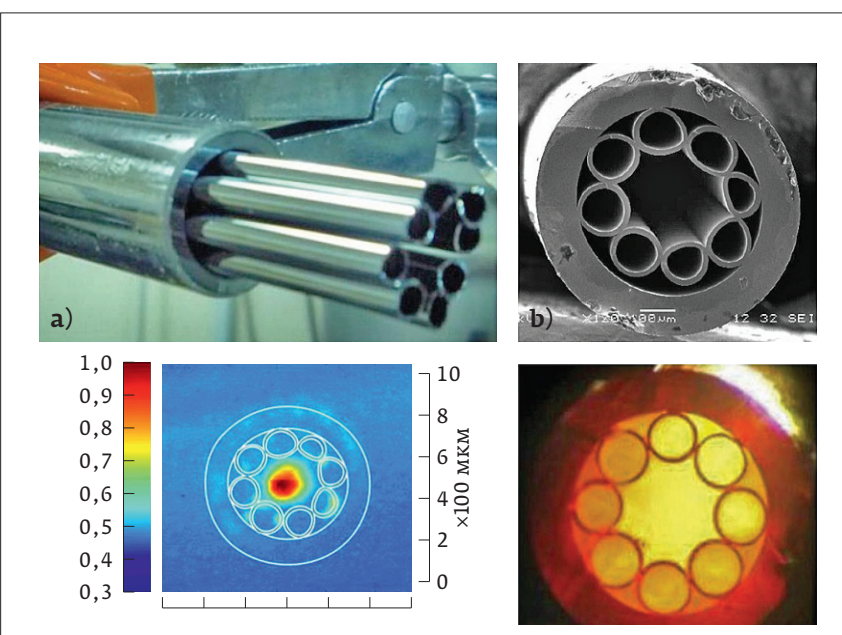

Puc. 8. а) заготовка РС из стекла $\mathrm{As}_{30} \mathrm{Se}_{50} \mathrm{Te}_{20}$, внешний / внутренний диаметр трубы $16 / 11$ мм, внешний / внутренний диаметр капияляров 3/2,4 мм; b) РС, полученный из данной заготовки (внешний диаметр световода 750 мкм); с) распределение интенсивности (в произв. ед.) излучения $\mathrm{CO}_{2}$-лазера на выходе данного световода (поверх распределения наложено схематичное изображение данного PC); d) поперечное сечение световода из стекла $\mathrm{As}_{2} \mathrm{~S}_{3}$ (внешний диаметр 820 мКм) 
Для изготовления световода использовалось высокочистое стекло состава $\mathrm{As}_{30} \mathrm{Se}_{50} \mathrm{Te}_{20}$, световод изготавливали методом "stack and draw". Опорную трубку изготавливали методом центробежного литья внутри вакуумированной кварцевой трубки. Капилляры изготавливали методом двойного тигля из расплава халькогенидного стекла. Исключение стадии получения стеклянной трубки методом центрифугирования для вытяжки капилляров позволило снизить вероятность кристаллизации халькогенидного стекла и тем самым полные оптические потери в световоде. Преформа представляла собой сборку из опорной стеклянной трубки и 8-ми капилляров с заданной геометрией и толщиной стенок, расположенных в один слой у внутренней стенки опорной трубки (рис. 8(a)).

Из полученной сборки-преформы был вытянут волоконный световод с внешним диаметром 750 мкм, диаметром сердцевины 260 мкм, толщина стенки капилляра составляла 13 мкм (см. рис. 8(b)). Оптические потери в этом световоде составили 11 дБ/м на длине волны 10,6 мкм. Световод транспортировал излучение $\mathrm{CO}_{2}$ лазера по полой сердцевине, что было зафиксировано с помощью тепловизора рис. 8(c).

Далее в 2014 году по аналогичной методике был изготовлен световод из более простого и технологичного халькогенидного стекла $\mathrm{As}_{2} \mathrm{~S}_{3}$ [47] (рис. 8(d)). Минимальные оптические потери в этом световоде составили 3 дБ/м на длине волны 4.8 мкм, причем в спектре потерь световода наблюдаются полосы поглощения типичных примесей, например: полосы S-H на 6,8; 4,1; 3,7 и 3,1 мкм; полосы от примеси $\mathrm{CO}_{2}$ на 4,31 и 4,34 мкм; ОН группы на 2,92 мкм; COS на 4,9 мкм, молекулярная $\mathrm{H}_{2} \mathrm{O}$ на 6,33 мкм. Что говорит о том, что значительная доля мощности в данном световоде распространяется по стеклу.

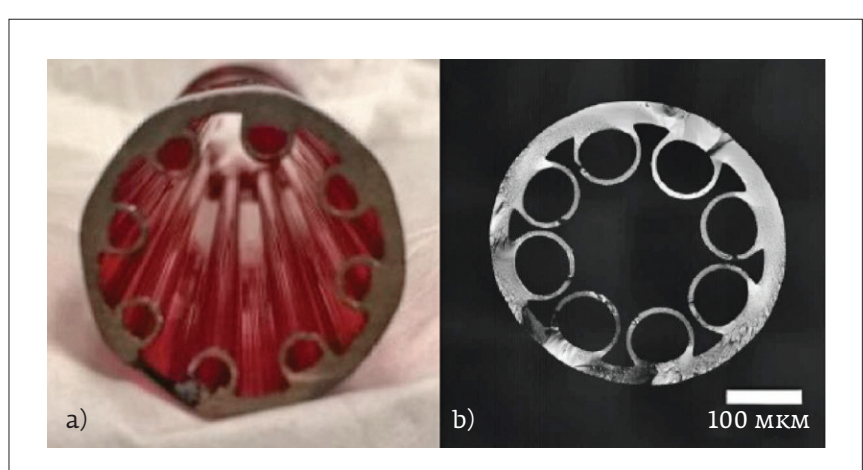

Puc. 9. (а) Преформа световода, полученная методом экструзии из стекла $\mathrm{As}_{2} \mathrm{~S}_{3}$; (b) PC из стекиа $\mathrm{As}_{2} \mathrm{~S}_{3}$ [48]
В 2015 году Gattass и др. использовали технологию экструзии для получения преформы револьверного световода из стекла $\mathrm{As}_{2} \mathrm{~S}_{3}$ [48]. В результате была получена преформа диаметром 18 мм и длиной 135 мм рис. 9(а). Световод, вытянутый из данной преформы, имел следующие геометрические размеры: диаметр сердцевины - 172 мкм, размеры овальных капилляров 70 на 75 мкм, толщина стенок капилляров - 7 мкм (рис. 9(b)). Оптические потери составили 2,1 дБ/ м на длине волны 10 мкм.

Во всех работах по халькогенидным РС проводились теоретические расчеты оптических потерь с использованием метода конечных элементов. При этом экспериментально измеренные потери практически всегда на несколько порядков величины превосходят теоретически рассчитанные значения. Наблюдаемое различие объясняется сильной чувствительностью оптических свойств световода к вариациям геометрических параметров получаемых структур. Повышенная чувствительность халькогенидных световодов к вариациям геометрических параметров, по сравнению с кварцевыми волокнами, обусловлена большим показателем преломления халькогенидных стекол, т.е. при тех же абсолютных вариациях геометрических толщин вариации оптических толщин в халькогенидных световодах оказываются в 3-4 раза больше, чем в кварцевых. Кроме того, зависимость вязкости халькогенидных стекол от температуры в несколько раз более резкая, чем зависимость вязкости кварцевого стекла от температуры (халькогенидные стекла являются "короткими"), т.е. при одинаковых температурных градиентах и температурных флуктуациях в процессе вытяжки качество халькогенидных микроструктурированных световодов оказывается ниже, чем кварцевых. Также очевидно, что чистота и однородность используемых халькогенидных стекол существенно уступает чистоте и однородности качественного кварцевого стекла, используемого при изготовлении РС.

Во всех работах по халькогенидным РС в спектрах потерь, полученных в результате теоретического моделирования, присутствуют частые резонансные пики. Данный факт объясняется резонансной связью мод полой сердцевины с модами оболочки. Похожие резонансные пики иногда наблюдаются в теоретически рассчитанных спектрах потерь кварцевых револьверных световодов на длинноволновом краю зон пропускания [9] (см. также [4], рис. 4). Однако в случае халькогенидных световодов изрезанность спектров пропускания наблюдается при математи- 
ческом моделировании практически всегда. Это происходит потому, что набор мод оболочки в случае халькогенидных РС более плотный вследствие высокого показателя преломления халькогенидных стекол. Но в эксперименте узких пиков оптических потерь в зонах прозрачности халькогенидных РС никогда не наблюдалось. По-видимому, из-за плохой геометрии изготавливаемых световодов реальные пики в спектрах потерь получаются уширенными.

\section{5. РАМАНОВСКИЕ ВОЛОКОННЫЕ ЛАЗЕРЫ НА РС, РАБОТАЮЩИЕ В СРЕДНЕМ ИК ДИАПАЗОНЕ}

Если сравнивать оптические потери в чистом кварцевом стекле и волоконных световодах с полой сердцевиной (см. рис. 3), то можно видеть, что если в УФ диапазоне достигнутые величины потерь для ПВС только сравнимы с потерями в v-SiO 2 , то в среднем ИК диапазоне ПВС имеют на несколько порядков более низкие потери и фактически открывают возможности для световодов из кварцевого стекла для работы в среднем ИК диапазоне, в частности для создания лазеров. Причем в настоящее время большинство наименьших значений экспериментально полученных данных по потерям ПВС в среднем ИК-диапазоне принадлежат именно РС (рис. 3).

На основе ПВС можно конструировать газовые волоконные лазеры. Такие лазеры способны сочетать в себе преимущества как волоконных лазеров (компактность, надежность, одномодовое излучение), так и газовых лазеров (широкий диапазон длин волн генерации, высокая выходная мощность, малая ширина линии генерации). Активной средой газовых волоконных лазеров служит газ, заполняющий полую сердцевину световода и обладающий дипольно-активными или комбинационно-активными переходами. При этом полый световод обеспечивает малый диаметр поля моды и большую длину взаимодействия излучения с активной средой, в результате чего пороги генерации лазеров на активных центрах и пороги нелинейных процессов, таких как, например, вынужденное комбинационное рассеяние (ВКР), могут быть снижены на несколько порядков по сравнению с неволноводными схемами.

В настоящее время активно ведутся работы по созданию газовых волоконных лазеров среднего ИК диапазона на основе эффекта ВКР в заполненных газами ПВС. В частности, на основе кварцевых РС продемонстрированы ВКР-лазеры, генерирующие на длинах волн от 2,9 до 4,4 мкм [42, 43, 49].
В большинстве работ газовые волоконные лазеры создаются по безрезонаторной однопроходной схеме [5, 50-53]. Благодаря высокой локализации излучения в сердцевине (d 5-50 мкм) на протяжении всей длины световода ( 1-10 м), полые световоды, заполненные активным газом, обеспечивают усиление за один проход, достаточное для развития генерации из квантовых шумов. Таким образом, однопроходная схема позволяет реализовывать эффективные газовые волоконные лазеры (ГВЛ) на основе как ВКР [5, 50, 52], так и инверсии населенностей [51]. Создание резонатора для ГВЛ на сегодняшний день остается технически сложной задачей, поскольку для полых световодов отсутствуют такие компоненты, как волоконные ответвители и аналоги волоконных брэгговских решеток. Тем не менее в нескольких работах исследовались резонаторные схемы ГВЛ с использованием кольцевого резонатора на объемных элементах [40] и резонатора, образованного брэгговскими решетками, подваренными к торцам активного полого световода [54].

В качестве активной среды газовых волоконных ВКР-лазеров интерес представляют легкие молекулярные газы, такие как легкий водород $\left({ }^{1} \mathrm{H}_{2}\right)$, дейтерий $\left(\mathrm{D}_{2}\right)$, метан $\left(\mathrm{CH}_{4}\right)$ или этан $\left(\mathrm{C}_{2} \mathrm{H}_{6}\right)$, поскольку они обладают большим рамановским сдвигом (4155 см-1, 2987 см$^{-1}, 2917$ см $^{-1}$ и 2954 см$^{-1}$ соответственно). Это обстоятельство открывает возможности для создания однокаскадных волоконных ВКР-лазеров среднего ИК диапазона, источником накачки для которых могут служить импульсные наносекундные эрбиевые волоконные лазеры, генерирующие в хорошо освоенном спектральном диапазоне около 1,5 мкм.

Ключевым компонентом для создания эффективных волоконных ВКР-лазеров среднего ИК диапазона является полый световод, характеристики которого должны удовлетворять определенным условиям. Необходимым условием для ВКР-генерации является превышение ВКР-усиления над величиной оптических потерь в световоде. Известно [55], что можно ввести своего рода параметр качества $\left(\mathrm{P}_{\mathrm{F}}\right)$, который характеризует световод как среду с ВКР-усилением:

$$
P_{F}=\left(\sqrt{\frac{\alpha\left(\lambda_{p}\right)}{g_{0}}}+\sqrt{\frac{\alpha\left(\lambda_{s}\right)}{g_{0}}}\right) .
$$

$\mathrm{P}_{\mathrm{F}}$ выражается через параметры световода: оптические потери на длине волны накачки $\alpha\left(\lambda_{p}\right)$, на длине волны стоксовой генерации $\alpha\left(\lambda_{s}\right)$ и коэффициента 

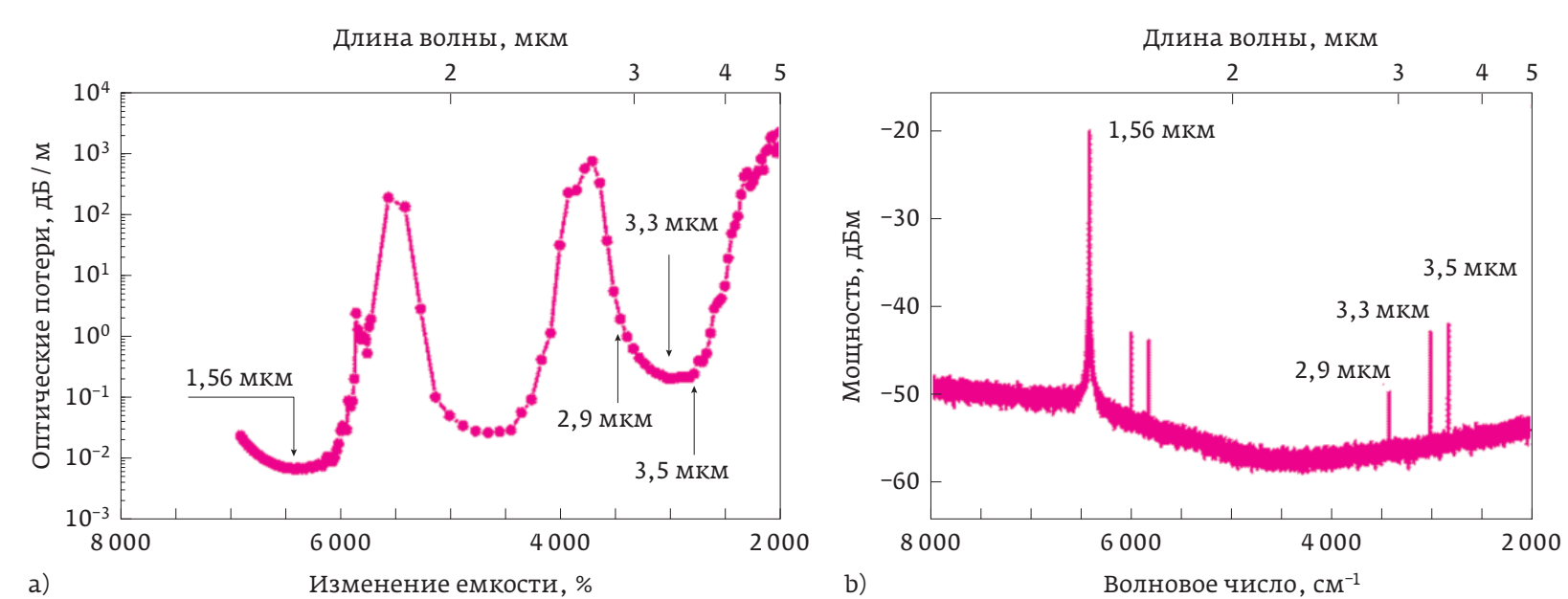

Puc. 10. (а) Cпектр оптических потерь световода с полой сердцевиной, разработанного для создания ГВЛ в спектральной области 2,9-3,5 мкм [49, 58]; (b) спектр излучения, измеренный в на выходе газового волоконного ВКР-лазера [58] (в качестве активной среды использовалась смесь молекулярных дейтерия и легкого водорода при комнатной температуре и парциальных давлениях 28 и 2 атм соответственно; пиковая мощность накачки на длине волны 1,56 мкм составляла $14 \mathrm{kBm}$ )

рамановского усиления волоконного световода $g_{0}$ (например, в дБ/(м×ВТ)) для рамановского преобразования $\lambda_{p} \rightarrow \lambda_{s}$. Физический смысл величины $P_{F}$, имеющей размерность мощности (Вт) заключается в следующем: это величина пороговой мощности накачки для рамановского лазера на рассматриваемом волоконном световоде, помещенном в некоторый высокодобротный резонатор. Поэтому чем меньше величина $P_{F}$, тем ближе световод по своим характеристикам к оптимальному для выбранного рамановского преобразования $\lambda_{p} \rightarrow \lambda_{s}$.

Известно, что для прямых (то есть не изогнутых) ПВ и ТВ оптические потери зависят от диаметра полой сердцевины как $1 / D^{3}$ и $1 / D^{4}$ соответ- $^{-}$ ственно [12, 14, 56]. Следовательно, для обоих моделей ПВ и ТВ в случае прямого волокна параметр качества $\mathrm{P}_{\mathrm{F}}$ пропорционален $1 / \mathrm{D}$ (для ПВ) и $1 / D^{2}$ (для ТВ), потому что $g_{0}$ пропорционален $1 / D^{2}$ (если эффективная площадь световода пропорциональна $\mathrm{D}^{2}$ ). Следовательно, чем больше $D$, тем меньше $P_{F}$. Таким образом, не существует оптимума для прямых световодов в зависимости от диаметра полой сердцевины. Ситуация изменяется, если учитывать потери, вызванные изгибом световода. Способность к изгибу является одним из основных преимуществ световодов. Предполагая, что мы работаем с ПВ и ТВ, которые намотаны с определенным радиусом R, вызванные изгибами потери в таких световодах пропорциональны диаметру полой сердцевины D. B результате оптические потери таких световодов имеют минимум при некотором значении диаметра полой сердцевины на любой определенной длине волны. Соответственно показатель качества $P_{F}$ достигает своего минимального значения при некотором диаметре полой сердцевины $\mathrm{D}_{\min }$, который определяет оптимальный диаметр сердцевины световода для рамановского преобразования. Если принять $\mathrm{R}=15$ см, а полая сердцевина заполнена водородом под давлением 30 атм, то, используя модели ПВ и ТВ, мы

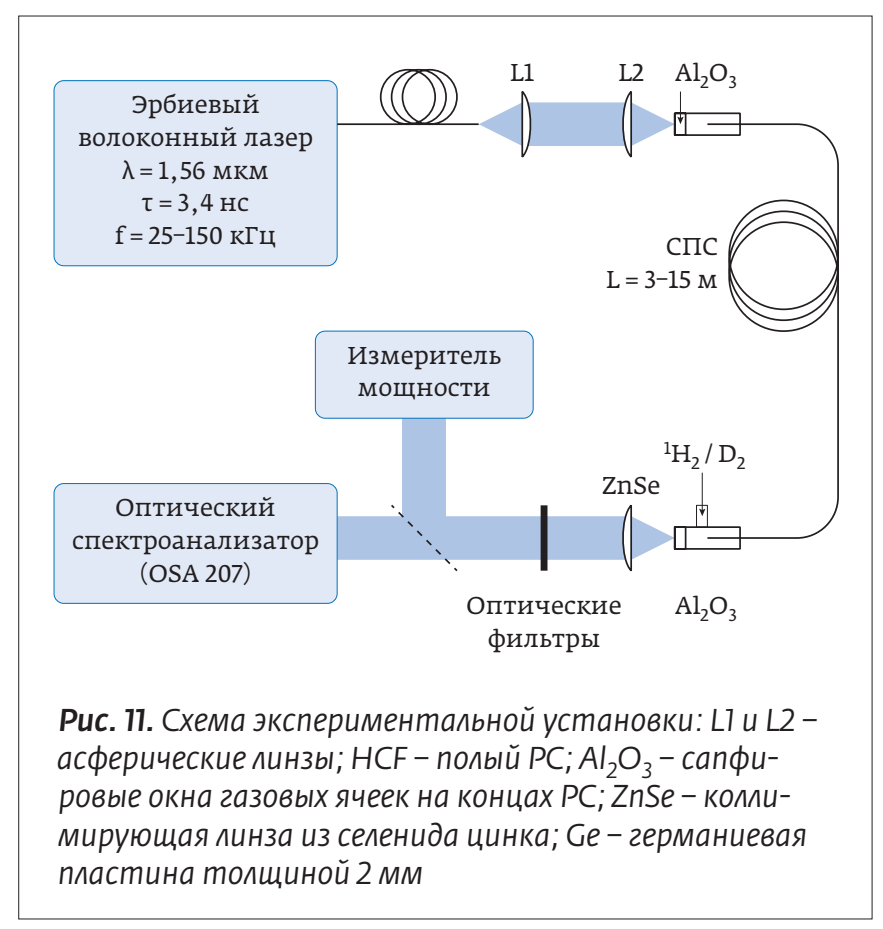


получим $D_{\min }$ >>75 мкм для обеих моделей. Гораздо более сложное численное моделирование реальных РС дает примерно то же значение [57].

При этом важно, что величина $P_{F}$ должна быть существенно ниже, чем доступная мощность излучения накачки. Оценим параметр $\mathrm{P}_{\mathrm{F}}$ для модельного световода с диаметром полой сердцевины 75 мкм $\left(A_{\text {eff }} \sim 2,4 \cdot 10^{-5} \mathrm{~cm}^{2}\right)$, заполненного молекулярным водородом при комнатной температуре и давлении $\geq 10$ атм $\left(g_{\mathrm{R}} \sim 1 \mathrm{~cm} /\right.$ ГВт, $\left.g_{0}=g_{\mathrm{R}} / A_{\text {eff }}\right)$. Счйтая оптические потери $\alpha_{p} \leq 0,1$ дБ/м (в ближнем ИК) и $\alpha_{s} \leq 1$ дБ/м (в среднем ИК) принципиально достижимыми в таком световоде, получим значение параметра качества $P_{F} \leq 100$ Вт. Пиковая мощность излучения, многократно превышающая данную величину, может быть достигнута с помощью существующих как твердотельных, так и волоконных импульсных лазеров наносекундной длительности. Однако следует отметить, что создание кварцевых полых световодов с уровнем оптических потерь $\leq 1$ дБ/м в среднем ИК-диапазоне представляет собой нетривиальную задачу, поскольку материальное поглощение квар цевого стекла в диапазоне длин волн 3-5 мкм резко возрастает от $\sim 50$ до $\sim 50000$ дБ/м. Тем не менее РС с примерно такими параметрами были созданы, и на их основе были созданы первые рамановские лазеры среднего ИК-диапазона.
В рамановских лазерах среднего ИК-диапазона до настоящего времени использовались однопроходные схемы, подобные представленной на рис. $11[58]$.

В работах $[49,58]$ в качестве активного использовался кварцевый револьверный световод, теоретический спектр пропускания которого показан на рис. 10(а). Длина световода составляла 15 м, диаметр поля моды был равен 45 мкм. При заполнении полой сердцевины молекулярным дейтерием $\mathrm{D}_{2}$ (парциальное давление 28 атм) с примесью молекулярного легкого водорода ${ }^{1} \mathrm{H}_{2}$ (парциальное давление 2 атм) была получена ВКР-генерация на длинах волн 2,9 мкм, 3,3 мкм и 3,5 мкм (рис. 10(b)). Пиковая мощность наиболее интенсивных спектральных компонент в среднем ИК составила $0,25 \mathrm{kBT}(\lambda=2,9$ мкм ) и $0,37 \mathrm{kBT}(\lambda=3,5 \mathrm{мкм})$, что соответствует средней мощности 23 и $37 \mathrm{MBT}^{\circ}$ соот- $^{-}$ ветственно. Квантовая эффективность преобразования составила $10 \%$ (для $\lambda=2,9$ мкм) и $6 \%$ (для $\lambda=3,5$ мкм) и допускает дальнейшую оптимизацию. Отметим, что, подбирая парциальные давления газов ${ }^{1} \mathrm{H}_{2}$ и $\mathrm{D}_{2}$ и регулируя мощность накачки, удавалось добиться преимущественной генерации на длине волны 2,9 либо 3,5 мкм.

В работах [42, 59, 60] конструкция РС была модифицирована таким образом, чтобы сдвинуть область его прозрачности в район 4 мкм (рис. 12a). Диаметр поля моды световода составил 56 мкм.

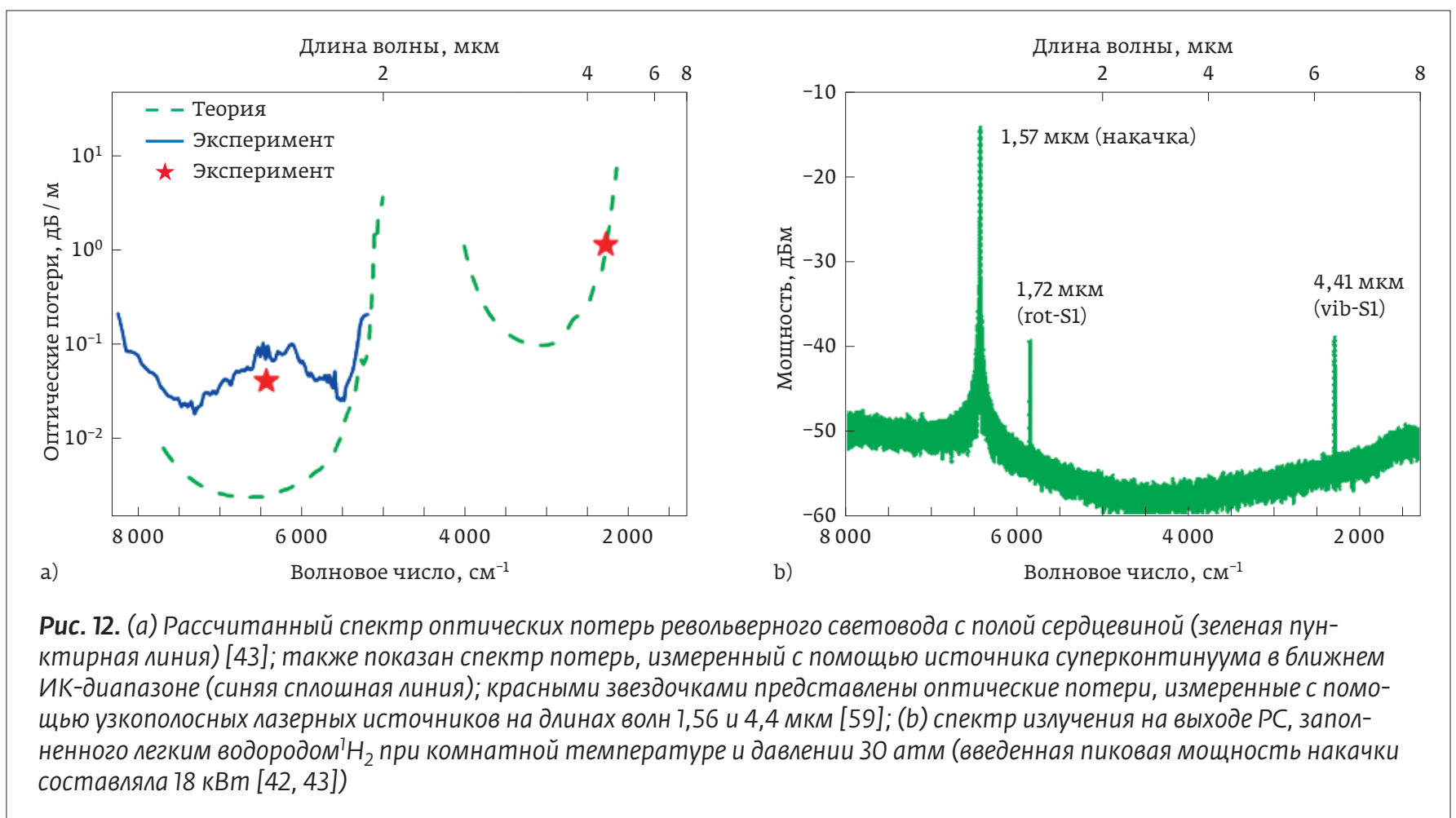

Photonics VOL. 13 № 52019 


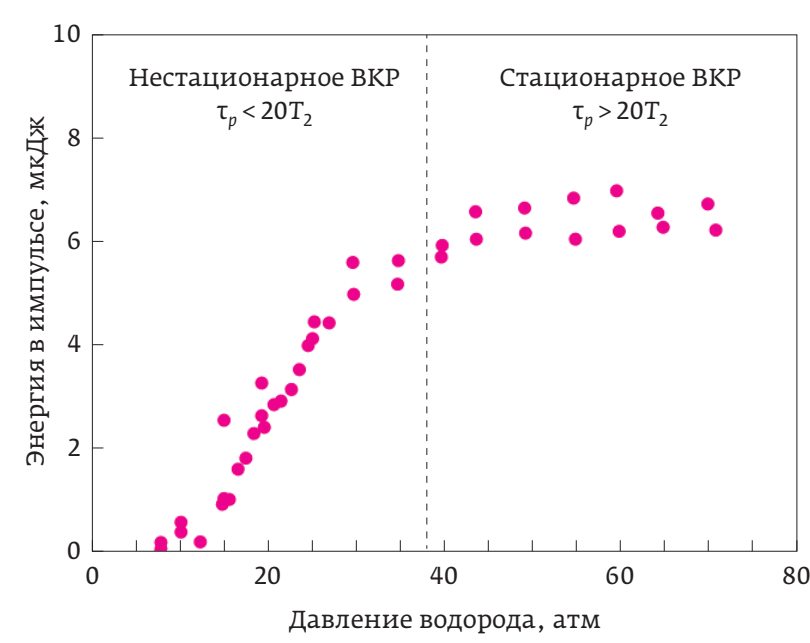

Puс. 13. Экспериментальная зависимость энергии импульса выходного излучения на длине волны 4,4 мкм от давления легкого водорода в полой сердцевине [59] (длительность импульсов накачки составляла $\tau_{p}=3,5$ нс, вертикальная пунктирная линия соответствует давлению 38 атм, при котором время поперечной релаксации молекулярных колебаний водорода составляет $T_{2}=0,175$ нс, удовлетворяя соотношению $\tau_{p}=20 \cdot T_{2}$ )

В таком световоде при наполнении его молекулярным водородом ${ }^{1} \mathrm{H}_{2}$ под давлением 30 атм в схеме, подобной представленной на рис. 11, была впервые получена рамановская генерация на длине волны 4,4 мкм (рис. 12b) [42, 60]. Используя одномодовое излучение такого лазера, были измерены оптические потери РС на длине волны 4,4 мкм, которые оказались равными 1,13 дБ/ м, в хорошем согласии с результатами численного моделирования такого световода (0,92 дБ/ м) [59]. Длина используемого РС в этих экспериментах составила $15 \mathrm{~m}$.

Путем численного решения системы уравнений связанных волн для колебательного ВКР в молекулярном водороде ${ }^{1} \mathrm{H}_{2}$ было проведено теоретическое рассмотрение ВКР генерации на длине волны 4,4 мкм. При этом были использованы измеренные значения оптических потерь 0,04 дБ/ м и 1,13 дБ/ м на длинах волн 1,56 и 4,4 мкм соответственно (рис. 12), а также значение коэффициента рамановского усиления $g_{\mathrm{R}}=0,43 \mathrm{~cm} / \Gamma \mathrm{\Gamma T}$, вычисленное для преобразования 1,56 $\rightarrow$ 4,4 мкм на основе известных данных о ширине линии и сечении рассеяния колебательного перехода $\mathrm{Q}(1)$ молекулы ${ }^{1} \mathrm{H}_{2}$ [61-63]. Оптимальная длина ВКР лазера, полученная при теоретическом рассмотрении, составила порядка 3,5 м, что существенно меньше длины полого световода (15 м), использованного в эксперименте [42, 43].
Одним из интересных результатов работы [59] является возможность сохранять стационарный режим ВКР при накачке газовых волоконных лазеров наносекундными импульсами. Известно [61], что если длительность импульса накачки ( $\left.\tau_{\mathrm{p}}\right)$ и время поперечной релаксации оптических фононов $\left(T_{2}\right)$ удовлетворяют соотношению $\tau_{\mathrm{p}} \leq 20 \cdot \mathrm{T}_{2}$, то ВКР-преобразование переходит в нестационарный режим, в котором коэффициент ВКР-усиления снижается. Для колебательного перехода Q(1) в молекулярном водороде при комнатной температуре и давлении 10 атм время поперечной релаксации составляет $\mathrm{T}_{2} \approx 0,64$ нс и, как следствие, импульсы накачки длительностью несколько наносекунд должны приводить к нестационарному режиму ВКР-генерации. Однако время $\mathrm{T}_{2}$ можно легко контролировать, изменяя давление газа, т.к. с ростом давления возрастает частота столкновения молекул, что приводит к более частому сбою фазы молекулярных колебаний и, соответственно, снижает величину $\mathrm{T}_{2}$. Указанный эффект наблюдался в [59] при изменении давления водорода в диапазоне 10-70 атм и позволил увеличить выходную мощность ВКР-лазера (рис. 13), накачка которого осуществлялась импульсами длительностью $\tau_{P}=3,5$ нс .

В результате оптимизации длины световода и давления водорода в полой сердцевине, а также использования линейно поляризованного излучения накачки на длине волны 1,56 мкм и схемы рамановского лазера, позволяющей сохранять поляризацию излучения, была достигнута квантовая эффективность 53\% для однокаскадного преобразования $1,56 \rightarrow 4,42$ мкм. Нам удалось продемонстрировать ВКР-генерацию наносекундных импульсов на длине волны 4,4 мкм со средней мощностью 1,4 Вт [64], при этом вращательные компоненты на длинах волн 1,72 и 1,91 мкм были существенно подавлены. На рис. 14 представлены спектр излучения на выходе такого ВКР-лазера и полученные для него зависимости выходной мощности от мощности накачки.

Продемонстрированная на сегодняшний день пиковая мощность импульсных наносекундных газовых волоконных ВКР-лазеров, генерирующих в области 3-5 мкм, составляет порядка 2 кВт [59]. Эта величина ограничена не характеристиками PC, а доступной мощностью волоконного эрбиевого лазера накачки. В недавних работах [65, 66] были продемонстрированы газовые волоконные ВКР-лазеры с выходной пиковой мощностью 400 кВТ и 150 кВТ на длинах волн 1,55 и 1,9 мкм соответственно. Применение таких лазеров в качестве источника накачки газонаполненных 

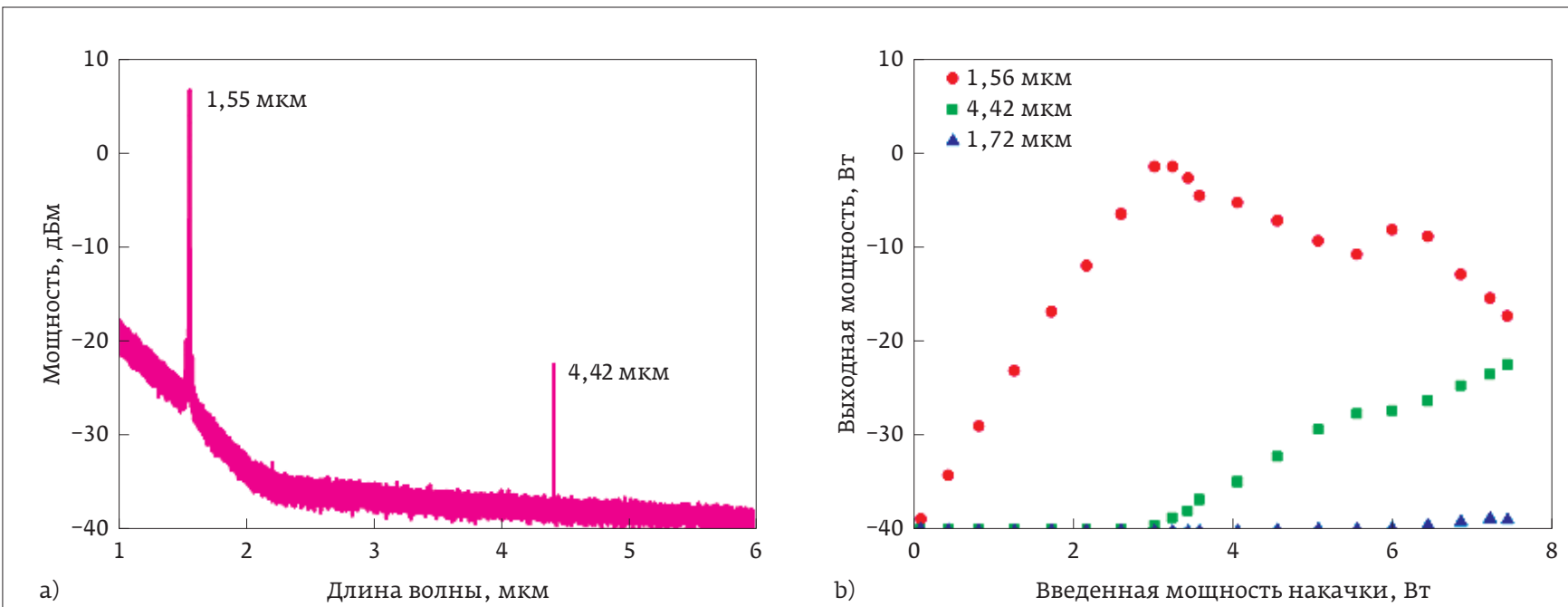

Puc. 14. (a) характерный спектр излучения на выходе газового волоконного ВКР-лазера; (b) зависимость средней мощности ВКР-лазера от средней мощности введенной в световод накачки (1,56 мкм) для прошедшей накачки, колебательной (4,42 мкм) и вращательной (1,72 мкм) компонент ВКР

кварцевых РС открывает путь к созданию эффективных газовых волоконных ВКР-лазеров, генерирующих наносекундные импульсы с пиковой мощностью 100 кВт в спектральном диапазоне 3-5 мкм. Кроме того, такие лазеры среднего ИК-диапазона могут быть реализованы за счет двухкаскадного ВКР в одном и том же отрезке РС, заполненного одним или несколькими газами.

Известно, что ВКР преобразование из ближнего $(\lambda=1,56$ мкм $)$ в средний ИК-диапазон $(\lambda=3 \div 5$ мкм $)$ сопровождается большим квантовым дефектом, который может затруднять получение высокой средней мощности на стоксовой длине волны. Однако в недавней работе [53], посвященной газовым волоконным лазерам на основе инверсии населенностей, была продемонстрирована эффективная генерация излучения на длине волны 3,1 мкм при накачке на $\lambda=1,53$ мкм. Несмотря на большой квантовый дефект, сопоставимый с квантовым дефектом в ВКР-лазерах, была достигнута выходная мощность более 1 Вт в непрерывном режиме. Данный результат подчеркивает возможности газовых волоконных лазеров на световодах с полой сердцевиной, в том числе и ВКР-лазеров, по генерации высокой средней мощности в среднем ИК диапазоне при большом квантовом дефекте и соответствующем энерговыделении в световоде.

\section{ЗАКЛЮЧЕНИЕ}

По сравнению с другими полыми световодами, РС отличаются прежде всего простотой конструкции. Будучи изготовлены из кварцевого стекла, они способны транспортировать излучение с длинами волн от вакуумного ультрафиолета до среднего ИК-диапазона. Экспериментально показано, что оптические потери в РС не превышают уровня порядка 1 дБ/м в диапазоне от 200 нм до 4,4 мкм. В ближнем ИК диапазоне полые фотоннокристаллические световоды (ФКС) демонстрируют более низкие потери (порядка 1 дБ/км на 1,5 мкм против 30 дБ/км в РС (см. рис. 3). Но в ФКС с полой сердцевиной излучение взаимодействует с несколькими периодами фотонного кристалла, что, с одной стороны, позволяет получить низкие оптические потери, а с другой, приводит к повышению оптических потерь в спектральных областях, где материал световода имеет высокие потери. РС, особенно с простыми капиллярами в оболочке (см. рис. 1(a, b)), характеризуются значительно меньшим перекрытием распределения излучения с материалом световода, что позволяет РС работать и в области высоких потерь материала оболочки. Поэтому на РС из кварцевого стекла были реализованы первые эффективные рамановские лазеры, работающие в среднем ИК-диапазоне (на длине волны 4,4 мкм). К достоинствам РС относится их способность транспортировать короткие мощные лазерные импульсы без искажений, что может найти и находит применение при доставке излучения от лазера к точке потребления. Этому способствуют их высокая лучевая прочность и низкая нелинейность [67]. Дальнейшее продвижение в средний ИК-диапазон возможен за счет перехода на халькогенидные РС. Первые эксперименты 
в этой области показали возможность транспортировки излучения $\mathrm{CO}_{2}$-лазера на $10,6 \mathrm{Mkм}$.

\section{СПИСОК ЛИТЕРАТУРЫ}

1. Pryamikov, A. D.; Biriukov, A. S.; Kosolapov, A. F.; Plotnichenko, V. G.; Semjonov, S. L.; Dianov, E. M. Demonstration of a waveguide regime for a silica hollow-core microstructured optical fiber with a negative curvature of the core boundary in the spectral region > $3.5 \mu \mathrm{m}$. Opt. Express. 2011; 19: 14411448. doi: https://doi.org/10.1364/OE.19.001441.

2. Wang, Y. Y.; Couny, F.; Roberts, P. J.; Benabid, F. Low loss broadband transmission in optimized core-shape Kagome Hollow-Core PCF. In Lasers and Electro-Optics (CLEO) and Quantum Electronics and Laser Science Conference (QELS), 2010 Conference on (2010); Lasers and Electro-Optics (CLEO) and Quantum Electronics and Laser Science Conference (QELS): San Jose, CA, USA, 2010; p. CPDB4.

3. Yu, F.; Wadsworth, W. J.; Knight, J. C. Low loss silica hollow core fibers for 3-4 $\mu$ m spectral region. Opt. Express. 2012; 20: 11153-11158. doi: https://doi. org/10.1364/OE.20.011153.

4. Kolyadin, A. N.; Kosolapov, A. F.; Pryamikov, A. D.; Biriukov, A. S.; Plotnichenko, V. G.; Dianov, E. M. Light transmission in negative curvature hollow core fiber in extremely high material loss region. Opt. Express. 2013; 21 9514-9519. doi: https://doi.org/10.1364/OE.21.009514.

5. Gladyshev, A. V; Kolyadin, A. N.; Kosolapov, A. F.; Yatsenko, Y. P.; Pryamikov, A. D.; Biryukov, A. S.; Bufetov, I. A.; Dianov, E. M. Efficient 1.9- $\mathrm{mm}$ Raman generation in a hydrogen-filled hollow-core fibre. Quantum Electron. 2015; 45: 807-812. doi:10.1070/OE2015v045n09ABEH015881.

6. Belardi, W. Design and Properties of Hollow Antiresonant Fibers for the Visible and Near Infrared Spectral Range. J. Light. Technol. 2015; 33: 4497-4503. doi:10.1109/JLT.2015.2477775.

7. Kosolapov, A. F.; Alagashev, G. K.; Kolyadin, A. N.; Pryamikov, A. D.; Biryukov, A. S.; Bufetov, I. A.; Dianov, E. M. Hollow-core revolver fibre with a reflecting cladding consisting of double capillaries. Quantum Electron. 2016; 46: 10-14. doi:10.1070/OEL15972.

8. Belardi, W.; Knight, J.C. Hollow antiresonant fibers with reduced attenuation. Opt. Lett. 2014; 39: 1853-1856. doi: https://doi.org/10.1364/ OL.39.001853.

9. Wei, C.; Weiblen, R.J.; Menyuk, C.R.; Hu, J. Negative curvature fibers. Adv Opt. Photonics. 2017; 9: 504-561

10. Marcatili, E. A. J.; Schmeltzer, R. A. Hollow Metallic and Dielectric Waveguides for Long Distance Optical Transmission and Lasers. Bell Syst. Tech. J. 1964; 43: 1783-1809. doi:10.1002/j.1538-7305.1964.tb04108.x.

11. Вайнштейн, Л.А. Электромагнитные волны. - М.: АСТ. 1988. Vajnshtejn, L. A. Elektromagnitnye volny. - M.: AST. 1988.

12. Miyagi, M.; Nishida, S. Transmission Characteristics of Dielectric Tube Leaky Waveguide. IEEE Trans. Microw. Theory Tech. 1980; 28, 536-541. doi:10.1109/ TMTT.1980.1130115.

13. Litchinitser, N. M.; Abeeluck, A. K.; Headley, C.; Eggleton, B. J. Antiresonant reflecting photonic crystal optical waveguides. Opt. Lett. 2002; 27:1592-1594, doi: https://doi.org/10.1364/OL.27.001592.

14. Zheltikov, A. M. Colors of thin films, antiresonant phenomena in optical systems, and the limiting loss of modes in hollow optical waveguides. Uspekhi Fiz. Nauk. 2008; 178: 619-629. doi:10.3367/UFNr.0178.200806d.0619.

15. Kosolapov, A. F.; Pryamikov, A. D.; Biriukov, A. S.; Vladimir, S.; Astapovich, M. S.; Snopatin, G. E.; Plotnichenko, V. G.; Churbanov, M. F.; Dianov, E. M. Demonstration of $\mathrm{CO}_{2}$-laser power delivery through chalcogenide-glass fiber with negative-curvature hollow core. Opt. Express. 2011; 19: 9-14. doi: https://doi.org/10.1364/OE.19.025723.

16. Vincetti, L.; Setti, V. Flexible tube lattice fibers for terahertz applications. Opt. Express. 2013; 21: 3388-3399. doi:10.1016/j.yofte.2012.09.008.

17. Kitamura, R.; Pilon, L.; Jonasz, M. Optical constants of silica glass from extreme ultraviolet to far infrared at near room temperature. Appl. Opt. 2007; 46: 8118-8133. doi: https://doi.org/10.1364/A0.46.008118.

18. Belli, F.; Abdolvand, A.; Chang, W.; Travers, J. C.; Russell, P. S. J. Vacuumultraviolet to infrared supercontinuum in hydrogen-filled photonic crystal fiber. Optica. 2015; 2: 292-300. doi: https://doi.org/10.1364/OPTICA.2.000292.

19. Humbach, O.; Fabian, H.; Grzesik, U.; Haken, U.; Heitmann, W. Analysis of $\mathrm{OH}$ absorption bands in synthetic silica. J. Non. Cryst. Solids. 1996; 203: 19-26, doi:10.1016/0022-3093(96)00329-8.

20. Tomashuk, A. L.; Golant, K. M. Radiation-resistant and radiation-sensitive silica optical fibers. In Proc. of SPIE; Moscow, Russian Federation. 2000; p. 188.

21. Kryukova, E. B.; Plotnichenko, V. G.; Dianov, E. M. IR absorption spectra in high-purity silica glasses fabricated by different technologies. In Proceedings of SPIE; Moscow, Russian Federation, 2000; 4083: 71-80.

22. Roberts, P.; Couny, F.; Sabert, H.; Mangan, B.; Williams, D.; Farr, L.; Mason, M.; Tomlinson, A.; Birks, T.; Knight, J.; St J Russell, P. Ultimate low loss of hollow-core photonic crystal fibres. Opt. Express. 2005; 13: 236-244, doi: https://doi.org/10.1364/OPEX.13.000236.

23. Fini, J. M.; Nicholson, J. W.; Windeler, R. S.; Monberg, E. M.; Meng, L.; Mangan, B.; DeSantolo, A.; DiMarcello, F. V. Low-loss hollow-core fibers with improved single-modedness. Opt. Express. 2013; 21: 6233-6242. doi:10.1364/OE.21.006233.

24. Wheeler, N.; Heidt, A.; Petrovich, M.; Baddela, N.; Numkam-fokoua, A.; Hayes, J.; Sandoghchi, S. R.; Poletti, F.; Wheeler, N. V; Heidt, A. M.; Baddela, N. K.; Fokoua, E. N.; Hayes, J. R.; Sandoghchi, S. R.; Petrovich, M. N.; Richardson, D. J. Low-loss and low-bend-sensitivity mid-infrared guidance in a hollow-core-photonic-bandgap fiber. Opt. Lett. 2014; 39: 295298. doi: https://doi.org/10.1364/OL.39.000295.

25. Wang, Y. Y.; Wheeler, N. V; Couny, F.; Roberts, P. J.; Benabid, F. Low loss broadband transmission in hypocycloid-core Kagome hollow-core photonic crystal fiber. Opt. Lett. 2011; 36: 669-671. doi: https://doi.org/10.1364/ OL.36.000669.

26. Février, S.; Beaudou, B.; Viale, P. Understanding origin of loss in large pitch hollow-core photonic crystal fibers and their design simplification. Opt. Express. 2010; 18: 5142-5150. doi: https://doi.org/10.1364/OE.18.005142.

27. Gérôme, F.; Jamier, R.; Auguste, J.-L.; Humbert, G.; Blondy, J.-M. Simplified hollow-core photonic crystal fiber. Opt. Lett. 2010; 35: 1157-1159. doi: https://doi.org/10.1364/OL.35.001157.

28. Urich, A.; Maier, R. R. J.; Yu, F.; Knight, J. C.; Hand, D. P.; Shephard, J. D. Flexible delivery of Er: YAG radiation at 2. $94 \mu \mathrm{m}$ with negative curvature silica glass fibers: a new solution for minimally invasive surgical procedures. Biomed. Opt. Express. 2013; 4: 7139-7144. doi: https://doi.org/10.1364/ BOE.4.000193.

29. Hartung, A.; Kobelke, J.; Schwuchow, A.; Wondraczek, K.; Bierlich, J.; Popp, J.; Frosch, T.; Schmidt, M. A. Double antiresonant hollow core fiber guidance in the deep ultraviolet by modified tunneling leaky modes. Opt. Express. 2014; 22: 19131. doi:10.1364/OE.22.019131.

30. Pryamikov, A. D.; Kosolapov, A. F.; Alagashev, G. K.; Kolyadin, A. N.; Vel'miskin, V. V; Biriukov, A. S.; Bufetov, I. A. Hollow-core microstructured "revolver» fibre for the UV spectral range. Quantum Electron. 2016; 46: 11291133. doi:10.1070/OEL16227.

31. Gladyshev, A. V; Kosolapov, A. F.; Kolyadin, A. N.; Astapovich, M. S.; Pryamikov, A. D.; Likhachev, M. E.; Bufetov, I. A. Mid-IR hollow-core silica fibre Raman lasers. Ouantum Electron. 2017; 47:1078-1082. doi:10.1070/ QEL16548.

32. Wang, Z.; Belardi, W.; Yu, F.; Wadsworth, W. J.; Knight, J. C. Efficient diode-pumped mid-infrared emission from acetylene-filled hollow-core fiber. Opt. Express. 2014; 22: 21872-8. doi:10.1364/0E.22.021872.

33. Michieletto, M.; Lyngsø, J. K.; Jakobsen, C.; Lægsgaard, J.; Bang, 0.; Alkeskjold, T. T. Hollow-core fibers for high power pulse delivery. Opt. Express. 2016; 24: 7103. doi:10.1364/OE.24.007103.

34. Uebel, P.; Günendi, M. C.; Frosz, M. H.; Ahmed, G.; Edavalath, N. N.; Ménard, J.-M.; Russell, P. S. J. Broadband robustly single-mode hollowcore PCF by resonant filtering of higher-order modes. Opt. Lett. 2016; 41: 1961. doi:10.1364/OL.41.001961.

35. Krylov, A. A.; Senatorov, A. K.; Pryamikov, A. D.; Kosolapov, A. F.; Kolyadin, A. N.; Alagashev, G. K.; Gladyshev, A. V.; Bufetov, I. A. $1.56 \mathrm{Mm}$ Sub-Microjoule Femtosecond Pulse Delivery Through Low-Loss Microstructured Revolver Hollow-Core Fiber. Laser Phys. Lett. 2017; 14: 035104 doi:10.1088/1612-202X/aa5a9b.

36. Gauthier, J.-C.; Fortin, V.; Carrée, J.-Y.; Poulain, S.; Poulain, M.; Vallée, R.; Bernier, M. Mid-IR supercontinuum from 2.4 to $5.4 \mu \mathrm{m}$ in a low-loss fluoroindate fiber. Opt. Lett. 2016; 41: 1756. doi:10.1364/ol.41.001756.

37. Tang, Z.; Shiryaev, V. S.; Furniss, D.; Sojka, L.; Sujecki, S.; Benson, T. M.; Seddon, A. B.; Churbanov, M. F. Low loss Ce-As-Se chalcogenide glass fiber, fabricated using extruded preform, for mid-infrared photonics. Opt. Mater. Express 2015; 5, 1722, doi:10.1364/OME.5.001722

38. Sanghera, J.; Aggarwal, I. D. Infrared Fiber Optics; CRC Press: Boca Raton, FL, USA. 1998; ISBN9780849324895 - CAT\# 2489.

39. Artyushenko, V.; Bocharnikov, A.; Sakharova, T.; Usenov, I. Mid-infrared 
Fiber Optics for 1-18 $\mu$ m Range. Opt. Photonik. 2014; 9: 35-39. doi:10.1002/ opph.201400062.

40. Hassan Muhammad Rosdi, A.; Yu, F.; J. Wadsworth, W.; Knight, J.C. Cavity-based mid-IR fiber gas laser pumped by a diode laser. Optica. 2016; 3: 218-221. doi:10.1364/OPTICA.3.000218.

41. Wei, C.; Hu, J.; Menyuk, C. R. Comparison of Loss in Silica and Chalcogenide Negative Curvature Fibers as the Wavelength Varies. Front. Phys. 2016; 4: 1-10. doi:10.3389/fphy.2016.00030.

42. Gladyshev, A. V; Kosolapov, A. F.; Khudyakov, M. M.; Yatsenko, Y. P.; Kolyadin, A. N.; Krylov, A. A. $4.4 \mu \mathrm{m}$ Raman Laser Based on Hydrogen-Filled Hollow-Core Silica Fiber. In Conference on Lasers and Electro-Optics; San Jose, California United States. 2017; p. JTh5A.7.

43. Gladyshev, A. V; Kosolapov, A. F.; Khudyakov, M. M.; Yatsenko, Y. P.; Kolyadin, A. N.; Krylov, A. A.; Pryamikov, A. D.; Biriukov, A. S.; Likhachev, M. E.; Bufetov, I. A.; Dianov, E. M. 4.4-um Raman laser based on hollow-core silica fibre. Quantum Electron. 2017; 47: 491-494. doi:10.1070/ QEL16400.

44. Gao, S.-F.; Wang, Y.-Y.; Ding, W.; Wang, P. Hollow-core negative-curvature fiber for UV guidance. Opt. Lett. 2018; 43: 1347. doi:10.1364/OL.43.001347.

45. Denisov, A. N.; Kosolapov, A. F.; Senatorov, A. K.; Pal'tsev, P. E.; Semjonov, S. L. Fabrication of microstructured optical fibres by drawing preforms sealed at their top end. Quantum Electron. 2016; 46:1031-1039. doi:10.1070/QEL16212

46. Yakovlev, A. I.; Snetkov, I. L.; Dorofeev, V. V.; Motorin, S. E. Magnetooptical properties of high-purity zinc-tellurite glasses. J. Non. Cryst. Solids. 2018; 480: 90-94. doi:10.1016/j.jnoncrysol.2017.08.026.

47. Shiryaev, V. S.; Kosolapov, A. F.; Pryamikov, A. D.; Snopatin, G. E.; Churbanov, M. F.; Biriukov, A. S.; Kotereva, T. V.; Mishinov, S. V.; Alagashev, G. K.; Kolyadin, A. N. Development of technique for preparation of As2S3 glass preforms for hollow core microstructured optical fibers. J. Optoelectron. Adv. Mater. 2014; 16: 1020-1025.

48. Rafael R. Gattass, Daniel Rhonehouse, Daniel Gibson, Collin C. McClain, Rajesh Thapa, Vinh O. Nguyen, Shyam S. Bayya, R. Joseph Weiblen, Curtis R. Menyuk, L. Brandon Shaw, and J. S. S. Infrared glass-based negativecurvature anti- resonant fibers fabricated through extrusion. Opt. Express. 2016; 24: 546-547. doi:10.1364/OE.24.025697.

49. Gladyshev, A.; Kosolapov, A. F.; Khudyakov, M. M.; Yatsenko, Y. P.; Senatorov, A. K.; Kolyadin, A. N.; Krylov, A. A.; Plotnichenko, V. G.; Likhachev, M. E.; Bufetov, I. A.; Dianov, E. M. Raman Ceneration in 2.9$3.5 \mu \mathrm{m}$ Spectral Range in Revolver Hollow-Core Silica Fiber Filled by H_2/D_2 Mixture. In Conference on Lasers and Electro-Optics. 2017; p. STu1K.2.

50. Benabid, F.; Knight, J. C.; Antonopoulos, G.; Russell, P. S. J. Stimulated Raman scattering in hydrogen-filled hollow-core photonic crystal fiber. Science. 2002; 298: 399-402. doi:10.1126/science.1076408.

51. Wang, Z.; Yu, F.; Wadsworth, W. J.; Knight, J. C. Efficient $1.9 \mu$ m emission in $\mathrm{H} 2$-filled hollow core fiber by pure stimulated vibrational Raman scattering. Laser Phys. Lett. 2014; 11, 105807, doi:10.1088/16122011/11/10/105807.

52. Benoit, A.; Beaudou, B.; Debord, B.; Gerome, F.; Benabid, F. High power Raman-converter based on $\mathrm{H} 2$-filled inhibited coupling HC-PCF. In Proc. SPIE10088; San Francisco, California, United States. 2000; p. 100880H.
53. Xu, M.; Yu, F.; Knight, J. Mid-infrared 1 W hollow-core fiber gas laser source. Opt. Lett. 2017; 42:4055. doi:10.1364/OL.42.004055.

54. Couny, F.; Benabid, F.; Light, P. S. Subwatt Threshold cw Raman Fiber-Gas Laser Based on $\mathrm{H} 2$-Filled Hollow-Core Photonic Crystal Fiber. Phys. Rev. Lett. 2007; 99: 143903. doi:10.1103/PhysRevLett.99.143903.

55. Bufetov, I. A; Dianov, E. M. A simple analytic model of a cw multicascade fibre Raman laser. Quantum Electron. 2007; 30, 873-877. doi:10.1070/ QE2000v030n10ABEH001840.

56. Miyagi, M. Bending losses in hollow and dielectric tube leaky waveguides. Appl. Opt. 1981; 20: 1221-1229. doi:10.1364/A0.20.001221.

57. Kolyadin, A. N.; Astapovich, M. S.; Gladyshev, A. V; Kosolapov, A. F. The Design Optimization and Experimental Investigation of the $4.4 \mu \mathrm{m}$ Raman Laser Basedon Hydrogen-filled Revolver Silica Fiber. In VII International Conference on Photonics and Information Optics; KnE Energy \& Physics: Moscow, 2018; Vol. 2018: 47-64

58. Gladyshev, A. V; Kosolapov, A. F.; Khudyakov, M. M.; Yatsenko, Y. P.; Kolyadin, A. N.; Krylov, A. A.; Pryamikov, A. D.; Biriukov, A. S.; Likhachev, M. E.; Bufetov, I. A.; Dianov, E. M. 2.9, 3.3, and $3.5 \mu$ m Raman Lasers Based on Revolver Hollow-Core Silica Fiber Filled by 1H2/D2 Gas Mixture. IEEE J. Sel. Top. Quantum Electron. 2018; 24: 0903008, doi:10.1109/JSTQE.2018.2810378.

59. Astapovich, M. S.; Kolyadin, A. N.; Gladyshev, A.; Kosolapov, A. F.; Pryamikov, A. D.; Khudyakov, M.; Likhachev, M. E.; Bufetov, I. A. Efficient $4.4 \mu \mathrm{m}$ Raman Laser Based on Hydrogen-Filled Hollow-Core Silica Fiber. arXiv:1801.01729.

60. Gladyshev, A. V.; Kosolapov, A. F.; Astapovich, M. S.; Kolyadin, A. N.; Pryamikov, A. D.; Khudyakov, M. M.; Likhachev, M. E.; Bufetov, I. A. Revolver Hollow-Core Fibers and Raman Fiber Lasers. 2018 Opt. Fiber Commun. Conf. Expo. 2018, M21.7. doi:10.1364/ofc.2018.m2j.7.

61. Hanna, D. C.; Pointer, D. J.; Pratt, D. J. Stimulated Raman Scattering of Picosecond Light Pulses in Hydrogen, Deuterium, and Methane. IEEE J. Quantum Electron. 1986; 22: 332-336. doi:10.1109/JQE.1986.1072945.

62. Weber, M. J. CRC Handbook of Laser Science and Technology Supplement 2: Optical Materials. In; CRC Press. 1994; p. 334. ISBN9780849335075.

63. Bischel, W. K.; Black, G. Wavelength dependence of raman scattering cross sections from 200-600 nm. In AIP Conference Proceedings; American Institute of Physics, 1983; Vol. 100:181-187.

64. Astapovich, M. S.; Gladyshev, A. V; Khudyakov, M. M.; Kosolapov, A. F.; Likhachev, M. E.; Bufetov, I. A. 4.4- $\mu \mathrm{m}$ Raman generation with an average power above I W in silica revolver fibre. Quantum Electron. 2018; 48:1084-1088. doi:10.1070/qel16836.

65. Chen, Y.; Wang, Z.; Gu, B.; Yu, F.; Lu, Q. Achieving a $1.5 \$ \mu \$ \mathrm{~m}$ fiber gas Raman laser source with about $400 \mathrm{~kW}$ of peak power and a $6.3 \mathrm{CHz}$ linewidth. Opt. Lett. 2016; 41: 5118-5121. doi:10.1364/0L.41.005118.

66. Wang, Z.; Gu, B.; Chen, Y.; Li, Z.; Xi, X. Demonstration of a 150-kW-peakpower, 2-CHz-linewidth, 1.9- $\mu \mathrm{m}$ fiber gas Raman source. Appl. Opt. 2017; 56: 7657-7661. doi:10.1364/AO.56.007657.

67. Колядин А. Н., Косолапов А. Ф., Буфетов И. А. Распространение оптического разряда по волоконным световодам с полой сердцевиной. Квантовая электроника. 2018; 48(12): 1138-1142.

Kolyadin A. N., Kosolapov A. F., Bufetov I. A. Optical discharge propagation along hollow-core optical fibres. Quantum Electron. 2018; 48(12): 1138-1142.

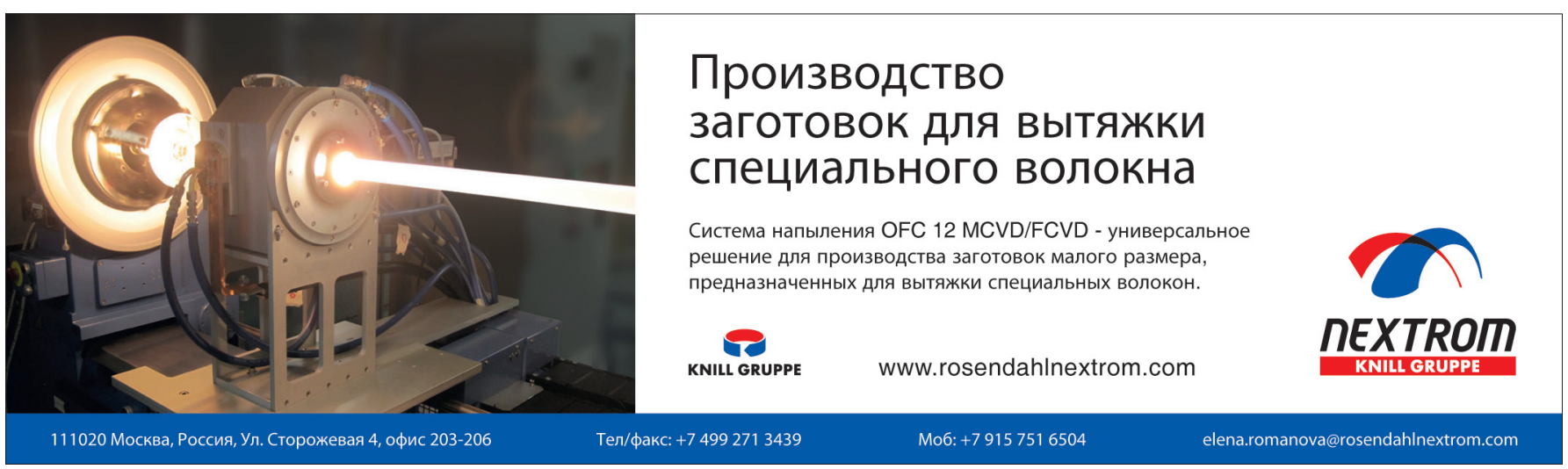

